\title{
Biotreatment of Industrial Wastewaters under Transient-State Conditions: Process Stability with Fluctuations of Organic Load, Substrates, Toxicants, and Environmental Parameters
}

\author{
JAN SIPMA, ${ }^{1,2}$ M. BEGOÑA OSUNA, ${ }^{1,3}$ MARIA A. E. EMANUELSSON, ${ }^{1}$ \\ and PAULA M. L. CASTRO ${ }^{1}$ \\ ${ }^{1}$ Escola Superior de Biotecnologia, Universidade Catolica Portuguesa, Rua Dr. Antonio \\ Bernardino de Almeida, 4200-072 Porto, Portugal \\ ${ }^{2}$ Laboratorium for chemical and environmental engineering (LEQUIA), Faculty of Sciences, \\ University of Girona, Campus de Montilivi 17071 Girona, Spain \\ ${ }^{3}$ CSIC-CEAB, Cala St Francesc 14, 17300 Blanes, Spain
}

Address correspondence to Jan Sipma, Escola Superior de Biotecnologia, Universidade Catolica Portuguesa, Rua Dr. Antonio Bernardino de Almeida, 4200-072 Porto, Portugal; Tel.: 34972 418804; Fax: 34972 418150; E-mail: jan.sipma@udg.edu

KEY WORDS: biological treatment, industrial wastewater, transient states, biomass retention, extracellular polymeric substances (EPS), adsorption, bioreactor stability, biomass dynamics

Biotreatment of industrial wastewater is often challenged by operation under transient states with respect to organic loads, pollutants, and physical characteristics. Furthermore, the potential presence of inbibitory compounds requires careful monitoring and adequate process design. This review describes difficulties encountered in biological treatment of wastewater with bighly variable influent characteristics. Typical design aspects of biological processes are presented and discussed with respect to their success in treating bighly fluctuating wastewaters. In general, biomass retention is a key factor for dealing with bighly fluctuating and/or inbibitory wastewater, but the how it operates also affects the stability of performance, as it was shown that dynamic operation instead of operation at a constant flow enhances biodegradation onset and more evenly distributed activity. Although ultimately stable effluent quality must be achieved, the microbial population stability is not necessarily bigh, as it was shown that microbial diversity and flexibility may play a critical role in functional stability. 


\section{INTRODUCTION}

The chemical industry is a vital sector of the European economy, for which the relatively complex synthetic routes employed lead to high volumes of waste produced that are generally considered difficult to treat biologically. Nevertheless, the biotreatment of both wastewaters and polluted air streams is advantageous over physical-chemical processes due to its complete mineralization potential and low costs. As the disposal of wastewater from industrial activities into municipal sewer systems is often no longer permitted, treatment of the wastewater generated has become an integrated part of the process in industrial operations. ${ }^{202}$ This has both advantages and disadvantages for its treatment. An important advantage is that biological treatment systems can be optimally designed to deal with the specific wastewater generated (e.g., using specific microorganisms for the pollutants present, or environmental conditions encountered, and to treat it directly at its source). Difficulties for the treatment of these types of wastewaters are mostly related to the high organic strength, the toxic compound load, or extreme environmental conditions encountered (e.g., $\mathrm{pH}$, temperature, and salinity, which are no longer diluted with domestic wastewater). Furthermore, due to the often limited amount of nutrients present in industrial effluents, the nutrient requirement needs to be carefully monitored for when needed nutrients should be supplemented to the wastewater to provide suitable conditions for the microorganisms acting in the biological conversion process. Although nutrient limitations may be an important cause of failure of the biological processes for industrial wastewater treatment systems, their occurrence and effects have not been included in this review.

Whereas domestic wastewater has a relatively constant homogenous composition, despite the occurrence of diurnal or seasonal variations, industrial wastewaters are often characterized by a high variability. Food processing industries often process different kinds of foods throughout the year, resulting in different wastewater characteristics leading to difficulties in its treatment due to the differences in COD concentration and composition. ${ }^{180}$ Recurring cleaning and disinfections of process parts, resulting in incidental shocks of cleaning products into the wastewater treatment system, has been shown to affect its efficiency. However, the choice of chemicals used can aid in relieving the toxicity of the wastewater. ${ }^{8,160}$ The production of fine chemicals and pharmaceuticals is dominated by batch processes, giving rise to rapid swings in the types and concentrations of organic pollutants appearing in their wastewaters. ${ }^{27,69,95,202}$ The latter can be referred to as 
wastewaters containing "sequentially alternating pollutants" (SAP), with pollutant composition alternating sequentially from one set of compounds to another over cycles of weeks or months. Many of the compounds used in chemical synthesis (e.g., phenols, chlorophenols, aldehydes, long chain fatty acids, aromatic compounds), even though biodegradable, are inhibitory at elevated concentrations. Therefore, sudden changes in their concentration may be highly detrimental to the treatment process and may result in a complete failure. Furthermore, advances in organic synthesis continuously lead to the introduction of new xenobiotic organic compounds (e.g., fluorinated molecules in pharmaceuticals), ${ }^{161}$ the fate of which in biotreatment processes is often uncertain. In addition to fluctuating loads and substrates, industrial wastewater systems may have to deal with more extreme operation conditions, such as acidity, alkalinity, or high salinity. All of these factors indicate that biological treatment of industrial wastewater, especially from the production of fine chemicals, is highly challenging.

Variations in flow rate and concentration add variability to the treatment operation, requiring more operator skills and careful monitoring to produce an acceptable treatment. ${ }^{51}$ Fluctuations in influent wastewater characteristics can be dampened by the provision of a flow equalization or buffer tank prior to the biological process. In many cases, wastewater treatment plants are normally run at a more constant flow rate because of such storage reservoirs provided in the system. ${ }^{51}$ Although flow equalization is determined based on hydraulics rather than concentrations, it often prevents biological downstream processes from shock loads or high concentrations of toxic chemicals and may further provide in-system $\mathrm{pH}$ neutralization, minimizing consumption of chemical requirements. ${ }^{53,194}$ However, unlike most domestic wastewater, the composition of wastewater from industrial operations varies widely depending on the function and activity of the particular industry. ${ }^{51,194}$ The variability is manifested in both flows and composition, and flow rate fluctuations of more than $50 \%$ due to production changes are not uncommon, though, unlike diurnal loads, they do not follow a regular pattern. ${ }^{28}$ Flow values and water quality measurements may vary by several orders of magnitude over a period of one year. ${ }^{194}$ Furthermore, highly variable concentrations of different components will make it impossible to achieve a uniform loading for all components. ${ }^{51}$ Because of such variability, it is often difficult to define typical operating conditions for industrial activities, ${ }^{51,194}$ which indicates that in such cases, flow equalization is likely of limited effectiveness. Moreover, weekly or monthly alternated production schemes that generate distinct wastewater characteristics, and for which flow equalization is ineffective, ensures the need for robust treatment processes capable to cope with considerable fluctuations.

In most studies on biological treatment of waste streams, the focus is on the reactor performance under steady-state conditions. However, biological wastewater treatment facilities never operate under steady-state conditions, 
as the microorganisms present function in gradients and are therefore subject to both unpredictable transient changes in process conditions and more predictable short-and longer-term cyclical physical and chemical changes. ${ }^{80}$ For the treatment of industrial wastewaters exposed to strong fluctuations in influent wastewater characteristics, knowledge on the performance under transient conditions is perhaps even more important, as it may ultimately determine the feasibility of a biological treatment process. An evaluation of reactor performance upon operational shocks (e.g., pH shocks, incidental occurrence of toxic concentrations, organic loading shocks, and starvation periods) provides valuable insight into reactor performance as well as biomass stability, activity, and diversity. Stable reactor performance is of great importance when aiming for a biological treatment of discontinuously produced and/or SAP containing industrial wastewater.

This review reports and discusses literature on the behavior of biological treatment processes for industrial wastewater focused on their performance under transient-state conditions. Bioreactor design considerations for the treatment of industrial wastewater, considered difficult to treat, are discussed, and interesting novel treatment processes are highlighted. Furthermore, process monitoring options and operation improvements are reported and discussed. This review aims to enhance the understanding of the difficulties in treating highly fluctuating and inhibitory compound containing wastewaters and discusses interesting biological treatment options to address the nature of these wastewaters.

\section{DIFFICULTIES ENCOUNTERED IN BIOLOGICAL TREATMENT OF INDUSTRIAL WASTEWATERS}

Inactivation of microbial metabolism, partially or complete, may result in a complete failure of biological wastewater treatment processes. It is therefore important to identify potential causes of biomass inactivation. Whereas domestic wastewater contains relatively low concentrations of organic matter and relatively moderate physical-chemical conditions, industrial wastewater can be characterized by high organic loads and/or extreme physical-chemical nature (e.g., pH, temperature, salinity). Furthermore, industrial wastewater is often laden with toxic compounds that may be biodegradable (e.g., phenols, chlorophenols, aromatics) or inert to biodegradation, such as heavy metals.

\section{High Organic Strength}

Domestic wastewater usually contains relative low COD concentrations (usually well below $\left.1000 \mathrm{mg} \mathrm{L}^{-1}\right),{ }^{194}$ whereas industrial operations often generate strong (>1000 $\mathrm{mg} \mathrm{L}^{-1}$ ) to extremely strong wastewaters. Extremely strong 
wastewaters, with COD concentrations that may even exceed 200 g. $\mathrm{L}^{-1}$, are generated in industries such as polyester manufacturing, ${ }^{145}$ olive mills, ${ }^{167}$ textile, ${ }^{46,50}$ and beverage production. ${ }^{21}$

Operation at high organic loading rates (OLRs) is limited by the amount of biomass, often a characteristic of a specific reactor design, and the desired overall removal efficiency. Industrial wastewater that contains extreme high concentrations of biodegradable organic matter requires either dilution or long hydraulic retention times (HRTs), which results in large reactors. ${ }^{145}$ As water is a valuable resource, dilution with fresh water cannot be considered. Furthermore, legislation increasingly prohibits the disposal of high-strength industrial wastewater to municipal sewage works, which may have functioned previously as the desired dilution process.

In principle, high COD loads do not have to pose a serious problem on biological wastewater treatment when sufficient long HRTs are applied. Nevertheless, problems are expected when the COD concentrations vary largely in the absence of measures to control the influent COD load. In aerobic treatment systems, the influent flow and thus the total load could be controlled based on the oxygen uptake rates (OUR). Because OUR can be derived rather easily from the dissolved oxygen (DO) concentrations and OUR respond rapidly on increased influent COD loads, it could be coupled to control the influent flow rate. ${ }^{149-151,211}$ In this manner, overloading of the biological reactor could be avoided, although a large buffer tank capacity would be required. Furthermore, this so-called event-driven timeoptimal-control regulates the feed rate to a sequencing batch reactor (SBR) to maintain a constant optimal substrate concentration, which minimizes reaction time ${ }^{211}$ and is estimated to save up to $25 \%$ on energy and increase the daily load that can be treated by $85 \%{ }^{150}$ Nevertheless, care should be taken in estimating the organic load from the OUR, as for readily degradable non-toxic compounds, an increase in load results in a higher OUR, but in the case of toxic compounds, the OUR decreases with increased load of toxicants, as shown for phenol. ${ }^{74}$

In anaerobic reactors, such as the upflow anaerobic sludge bed (UASB) reactors (see Figure 1A), despite the fact that much higher OLRs can be applied compared to activated sludge systems, the syntrophic interactions needed for the complete biodegradation of organic matter may be negatively affected by strong fluctuations in influent concentrations. Such fluctuations are likely to upset the balance between the different trophic groups involved in the biodegradation processes and may ultimately lead to low treatment efficiencies. ${ }^{123}$ Nachaiyasit and Stuckey ${ }^{158}$ summarized the general responses of anaerobic processes to organic shocks as follows:

- increased effluent volatile fatty acid concentrations;

- decreased removal efficiencies; 

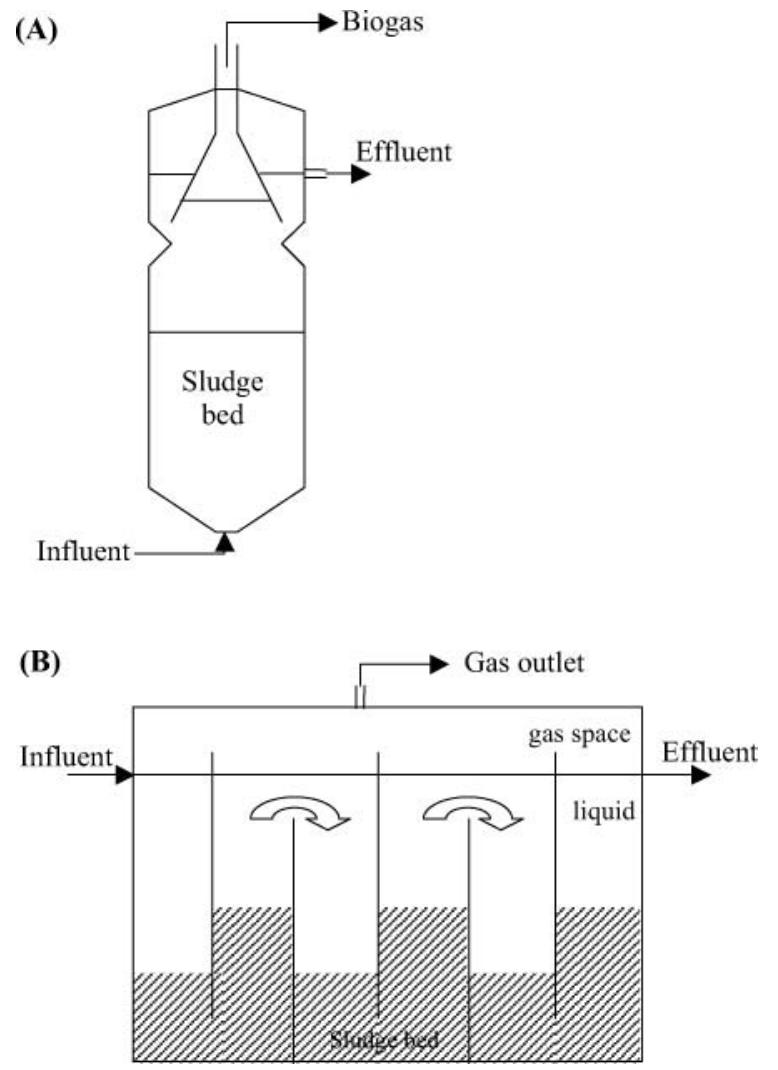

FIGURE 1. Schematic representation of two anaerobic bioreactor for wastewater treatment: a) upflow anaerobic sludge bed reactor (UASB); b) anaerobic baffled reactor (ABR).

- decreased $\mathrm{CH}_{4}$ content at increased biogas production;

- increased effluent suspended solids;

- increased sludge volume index;

- increased fraction of post-acidogenic microorganisms; and

- increased or decreased $\mathrm{pH}$, depending on the buffer capacity of influent and system.

While both an organic shock at constant HRT and a constant concentration at hydraulic shocks may result in the same OLR, their influence on reactor performance is different. For an increased concentration, mixing is only increased by an enhanced gas production and mass transfer increases, whereas with a hydraulic shock, the mixing increases due to increased gas production, and hydraulic shear and mass transfer remain equal. ${ }^{159}$ The latter may result in potential washout of biomass.

Unfortunately, in-line control of the COD load to anaerobic reactors is not as simple as is proposed for its aerobic counterpart. The high biomass 
concentration employed in anaerobic reactors usually aims to increase stability rather than improve COD removal. ${ }^{158}$ Nachaiyasit and Stuckey ${ }^{158,159}$ reported that the stability of anaerobic wastewater treatment processes exposed to greatly varying loads is considerably enhanced in anaerobic baffled reactors (ABR; see Figure $1 \mathrm{~B}$ ), in which the sludge is physically separated in various reactor compartments. This prevents a large part of the biomass from being exposed to low $\mathrm{pH}$ values due to accelerated acidogenesis. In principle, for anaerobic treatment, analogue to the use of the OUR in aerobic systems, direct gas measurements could be used to control the influent flow rate. Rather than the amount of gas production, the composition of the produced biogas contains important information on the balance of the syntrophic interactions. High organic loads often coincide with increased $\mathrm{CO}_{2}$ fractions in the biogas, ${ }^{158}$ which are caused by the higher growth rates of acidogenic organisms compared to methanogens ${ }^{195}$ and results in a disturbance of the population balance. These disturbances often lead to acidification within the bioreactor and consequently a decreased efficiency. In anaerobic treatment the monitoring of carbon monoxide has been proposed, as after substrate perturbations, carbon monoxide was found to accumulate in the produced biogas. ${ }^{84}$ However, Bae and McCarty 9 later concluded that inconsistencies in the production of carbon monoxide after substrate perturbations prevent the use of carbon monoxide as a reliable monitoring tool. More recent attempts of using carbon monoxide as a monitoring tool for identification of anaerobic process perturbations have not been found in literature.

\section{Wastewaters Characterized by the Presence of Sequentially Alternating Pollutants}

SAP scenarios in biological waste treatment systems have not received much attention, and when investigated, it has mostly been done for waste gas treatment. ${ }^{29,48,148}$ In these studies, the change of pollutant fed to the biofilter generally required only a short period in the range of hours to return to previous removal efficiencies. With changes in industrial processes, not only can the waste gas composition change, but also the composition of the wastewater. Unlike with waste gas treatment, regularly occurring shortterm breaks (e.g., due to weekend breaks, daytime operation, short maintenance interruptions) will not create any problem, as these do not affect the wastewater treatment system when sufficient buffer capacity is installed. However, when the production processes change periodically, leading to changing characteristics of the wastewater in terms of concentrations, composition, and perhaps even environmental conditions, this may complicate the biological treatment drastically. These SAP scenarios have received little attention in studies for wastewater treatment. SAP scenarios in their most extreme form are similar to periods of starvation (i.e., when the different 
pollutants are degraded by specific microorganisms that cannot metabolize the pollutant present in the subsequent period). In suspended cultures, this will easily result in washout of specific microorganisms during starvation periods. Ferreira Jorge and Livingston ${ }^{67}$ investigated the use of maintenance feeding by artificially supplying a small flow of the compound from which the microorganisms were starved, but had to conclude that the excessive amount of carbon fed as maintenance feed made this strategy unfeasible. Ferreira Jorge and Livingston ${ }^{68}$ later demonstrated that an extractive membrane bioreactor, in which a biofilm developed on the membrane surface, could handle changes in wastewater composition alternating from monochlorobenzene to 1,2-dichloroethane. This shows that biomass retention is of eminent importance for the treatment of wastewaters characterized by SAP.

\section{Extreme Environmental Conditions of $\mathrm{pH}$ and Salinity}

The treatment of specific industrial wastewater streams can be complicated by its physical chemical characteristics. Most wastewater treatment systems operate at near neutral $\mathrm{pH}$, low salinity, and moderate temperatures. Although several microorganisms have been isolated showing growth and metabolism at $\mathrm{pH}$ values as high as $11,{ }^{142}$ the best and easiest way to deal with strongly fluctuating influent $\mathrm{pH}$ values is most likely through its neutralization or equalization at a desired $\mathrm{pH}$. The latter would be especially interesting when neutralization requires excessive use of chemicals (e.g., in the biological treatment of spent caustics from the petrochemical industry with a $\mathrm{pH}$ that typically exceeds 12 ). ${ }^{175}$ Chong et al. ${ }^{35}$ tried to bioaugment an alkaline-tolerating culture in an activated sludge treatment system that suffered from shocks up to $\mathrm{pH} 12$; however, they did not succeed due to the wash-out of the bioaugmented culture within 1 sludge retention time (SRT). In case of the treatment of specific industrial waste streams with a constant extreme high or low $\mathrm{pH}$, the inoculation with cultures capable of growth and metabolism at these conditions ${ }^{142}$ will most likely show better results. Incidental $\mathrm{pH}$ shocks might also affect the trace elements availability required for growth as shown for short-term mild acidic $\mathrm{pH}$ shocks $\mathrm{pH}$ 5) on anaerobic granular sludge fed with methanol. ${ }^{242}$ Zandvoort et al. ${ }^{242}$ found translocation as well as significant losses of metals within the anaerobic sludge granules, and after a four-day shock of $\mathrm{pH} 5$, this resulted in the accumulation of volatile fatty acids (VFA) and methanol in the effluent.

Lefebvre and Moletta ${ }^{122}$ reviewed the treatment of industrial saline wastewaters (e.g., from petroleum refining, textile processing, leather processing, and food conservation) and reported that in addition to the inhibition of many microorganisms at high salt concentrations, flocculation may be affected negatively due to the low quantity of filamentous bacteria. Furthermore, the lack of protozoans results in the absence of grazing of small 
flocs or suspended solids, which together with a greater resistance to settling due to the higher density of salt water results in increased suspended solids concentrations in the effluent and thus higher effluent COD levels. ${ }^{122}$ High salt concentrations in wastewaters are often coinciding with a high $\mathrm{pH}$ (e.g., in petroleum-refining industries where $\mathrm{NaOH}$ solutions are used to remove $\mathrm{H}_{2} \mathrm{~S}$ ) ${ }^{175}$ Furthermore, a build-up of salinity is expected to occur in wastewater treatment systems where the process water is treated and reused in the process. This is especially the case in industrial processes consuming large amounts of water (e.g., in the textile industry and pulp and paper mills), where the minimization of effluent volumes recently received much attention. ${ }^{46,207,208}$ Highly fluctuating salinity will most likely not occur often other than for incidental spills of highly saline streams. Nevertheless, Woolard and Irvine ${ }^{235}$ reported that a mixed culture of halotolerant and halophilic phenol-degrading microorganisms in a sequencing batch biofilm reactor showed stable operation and complete phenol removal even when step changes of $14 \%$ in the salt concentration were imposed.

Unidentified halophilic bacteria, isolated from the Great Salt Lake, were used in the treatment of hypersaline wastewaters in a periodically operated sequencing batch biofilm reactor. ${ }^{234}$ This process could remove more than 99\% of phenol from a synthetic waste brine at average influent concentrations of $0.1-0.13 \mathrm{~g} \mathrm{~L}^{-1}$ in the presence of $15 \% \mathrm{w} / \mathrm{v} \mathrm{NaCl}$. A stable high-quality effluent was obtained despite fluctuations in influent phenol concentrations. Hinteregger and Streichsbier ${ }^{85}$ successfully achieved biotreatment of a synthetic saline phenolic wastewater from the oil industry using a moderately halophilic Halomonas sp. in a bubble reactor. This strain fully degraded 0.1 $\mathrm{g}$ phenol $\mathrm{L}^{-1}$ as the sole carbon and energy source within $13 \mathrm{~h}$ in the presence of $1-14 \% \mathrm{w} / \mathrm{v} \mathrm{NaCl}$. Phenol degradation at $\mathrm{NaCl}$ concentrations at or below $5 \% \mathrm{w} / \mathrm{v}$ was accompanied by the accumulation of an intermediate of the ortho-cleavage pathway, identified as cis,cis-muconic acid. The amount of this compound, which is a potentially useful raw material for functional resins, pharmaceuticals, and agrochemicals, could be raised six-fold by increasing the phenol concentration from 0.1 to $0.6 \mathrm{~g} \mathrm{~L}^{-1}$.

Another approach to extend the capacity of efficient hydrocarbon degraders for biodegradation in saline environments has been performed by impairing the phenotype of osmotolerance to a crude oil-degrading consortium, consisting of four Pseudomonas strains. ${ }^{97}$ The osmoregulatory E. coli pro $U$ operon was subcloned and expressed into each member of the consortium, after which the organisms could grow in the presence of $6 \% \mathrm{w} / \mathrm{v} \mathrm{NaCl}$, whereas the expression of the salt tolerance did not hamper hydrocarbon degradation capacity. ${ }^{97}$ However, the ability of such constructed microorganisms to survive under in situ conditions has yet to be demonstrated. Boon et al. ${ }^{19}$ showed that degradation of 3-chloroaniline decreased in time after bioaugmentation of an activated sludge plant with an indigenous $\mathrm{CO}^{-}$ mamonas testosteroni strain. This indicates that bioaugmentation, even with 
a strain originating from the ecosystem and able to grow effectively on a specific substrate that is present, is not permanent and will probably require regular resupplementation. In general, the addition of specialized strains to wastewater treatment systems is not yet widely applied, as bioaugmentation is less predictable and controllable than the direct destruction of contaminants by methods such as incineration. ${ }^{19}$ McClure et al. ${ }^{143}$ also observed that bioaugmentation of an activated sludge plant with high concentrations of genetically engineered microorganisms (GEM) for the degradation of 3chlorobenzoate did not enhance the degradation rate. The appearance of an indigenous 3-chlorobenzoate degrader appeared detrimental on the survival of the GEM, which illustrates the importance of choosing strains that are well suited for the prevailing environmental conditions. ${ }^{143}$

In general, both $\mathrm{pH}$ and salinity may give rise to difficulties in the treatment of industrial waste streams. Nevertheless, the isolation of microorganisms from extreme environments capable of degradation of a widerange of hydrocarbons, chlorinated hydrocarbons, and phenols ${ }^{4,142}$ represents a promise for the treatment of industrial acidic, saline, and/or alkaline wastewaters.

\section{Effect of Temperature and Temperature Transients}

Most aerobic wastewater treatment plants are operated at ambient temperatures around $20^{\circ} \mathrm{C}$, whereas anaerobic treatment facilities are usually operated at elevated temperatures of $30-35^{\circ} \mathrm{C}$. As most wastewaters, domestic and industrial, are generated below $20^{\circ} \mathrm{C},{ }^{126}$ anaerobic treatment at low temperatures would reduce the energy requirements for heating drastically. ${ }^{60}$ Lettinga et al. ${ }^{126}$ wrote that prejudice and serious lack of insight in the established sanitary wastewater-engineering world prevents the use of anaerobic wastewater treatment of cold wastewater. Nevertheless, recent studies have shown that anaerobic wastewater treatment can be successfully achieved at low temperatures, ${ }^{176}$ even with difficult industrial wastewaters containing toluene, ${ }^{61} 2,4,6$ trichlorophenol, ${ }^{37}$ or methanol, propanol, and acetone. $^{60}$

As several industries generate high-temperature wastewater, the use of thermophilic biological processes becomes interesting, as cooling and heating for its treatment in the mesophilic temperature range could be avoided, which is especially important for water reuse as process water. ${ }^{200,207,208}$ Anaerobic thermophilic $\left(55^{\circ} \mathrm{C}\right)$ wastewater treatment has been demonstrated successfully, ${ }^{177,205,206}$ although literature reports revealed that thermophilic wastewater treatment systems are often more sensitive to environmental changes than the well-defined high-rate mesophilic systems. ${ }^{203}$ In contrast, aerobic wastewater treatment processes at high temperatures $\left(55-65^{\circ} \mathrm{C}\right)$ have 
been applied in full-scale, only limited. ${ }^{114,115}$ It is often assumed that the oxygen mass transfer rate will decrease with increased temperatures due to the lower oxygen saturation concentration at higher temperatures. Vogelaar et al., ${ }^{213}$ however, showed that this oxygen transfer rate is similar between 20 and $55^{\circ} \mathrm{C}$, as the lower saturation concentration (i.e., the driving force for $\mathrm{O}_{2}$ mass transfer) is fully compensated by increases in diffusion rates and decreases in liquid viscosity and surface tension, leading to a higher $\mathrm{k}_{L}$ a value. Successful applications of thermophilic aerobic treatment processes have been reported despite that results were generally superior in the mesophilic temperature range. $88,115,189,200,214-216$ Nevertheless, Luvsanjamba et al. ${ }^{137}$ obtained better results for thermophilic biotrickling filtration of a waste stream containing isobutyraldehyde and 2-pentone compared to operation at $25^{\circ} \mathrm{C}$. In this study, thermophilic treatment resulted in lower biomass accumulation and foam formation, which resulted in a higher maximum removal capacity.

Whereas operation at high or low temperatures may present their difficulties (mainly in the design of a treatment system), temperature fluctuations may affect its performance more directly. Sewage treatment systems may experience mainly seasonal changes, of which the reduced microbial activity in the winter represents the biggest challenging. ${ }^{153}$ In general, these temperature changes are moderate and within the growth boundaries of the mesophilic microorganisms present. Industrial treatment systems can be subjected to frequent and drastic temperature changes that affect their performance, such as due to the operation of batch units and shutdowns/startups of processes. ${ }^{153}$ The most serious effects on the established biological populations are expected when temperature changes alternate from the mesophilic to thermophilic range. Morgan-Sagastume and Allen ${ }^{153}$ proposed a wastewater temperature upshift from $30-35^{\circ} \mathrm{C}$ to $40-45^{\circ} \mathrm{C}$ during summer for industrial effluents (e.g., from the pulp and paper industry) to limit the costs for cooling. The COD removal efficiency decreased due to this temperature upshift in an aerobic SBR by about 20\%, although with time, the COD removal efficiency increased gradually to nearly similar values as found previously at $35^{\circ} \mathrm{C} .{ }^{153}$ It suggests that this temperature shift resulted in a gradual development of a novel microbial community. This is in agreement with the community structure analysis of aerobic synthetic wastewater treatment by LaPara et al., ${ }^{115}$ who observed distinct populations at temperatures between 25 and $65^{\circ} \mathrm{C}$ in denaturing gradient gel electrophoresis. Population changes are also commonly witnessed in anaerobic thermophilic wastewater treatment, for which mesophilic anaerobic sludge is used as inoculum due to the limited availability of thermophilic sources. ${ }^{125,203,204}$ Temperature oscillations from $31.5^{\circ} \mathrm{C}$ to $40^{\circ} \mathrm{C}$ in an aerobic SBR only slightly affected the COD removal efficiency, but caused a deterioration of the sludge settleability. ${ }^{153}$ 


\section{Presence of Toxic Compounds}

Peak levels of toxic compounds present in wastewater or waste air can cause a complete failure of biological treatment. Industrial wastewaters may contain a large variety of potentially inhibiting or toxic compounds (e.g., aromatics, phenols, chlorinated or fluorinated compounds, volatile organic compounds [VOC], heavy metals, surfactants, biocides). These compounds may either appear constantly in the effluent from industrial operations or incidentally due to spills or batch production schemes. In order to prevent malfunction of the biological treatment process, it is important to evaluate the potential risk compounds present in a specific waste stream.

Some of the toxic compounds may be mostly inert to biodegradation and may require additional physical-chemical treatment, either as pre- or posttreatment depending on their effects on the biological process (e.g., heavy metals). Other compounds may be persistent to biodegradation under the conditions encountered in most wastewater treatment processes, and in some cases the combination of physical-chemical treatment with biological treatment could be beneficial. The enhancement of biodegradability of industrial wastewater by chemical oxidative pre-treatment has recently been reviewed extensively by Mantzavinos and Psillakis. ${ }^{141}$ Chemical oxidation processeseither wet air oxidation or advanced oxidation processes (AOX) that use ozone, $\mathrm{H}_{2} \mathrm{O}_{2}$, Fenton's reagent, or UV-are costly, especially when complete oxidation is desired. ${ }^{141}$ Therefore, for persistent organic compounds, partial chemical oxidation is increasingly considered, aiming to enhance the biodegradability of the persistent compound in the subsequent biological process. ${ }^{14,49,121}$ For that, the used AOX should ideally be highly selective towards these persistent compounds. ${ }^{141}$ However, most AOX depend on the formation of the highly reactive but poorly selective hydroxyl radicals, and only ozone at low or neutral $\mathrm{pH}$ can selectively oxidize certain specific compounds. ${ }^{141}$ Moreover, toxicity does not necessarily decrease when AOX are applied, and has even in several cases been shown to increase during early stages of oxidation. ${ }^{141}$

The majority of toxic compounds is probably susceptible to biodegradation, provided that suitable conditions for growth of the specific degrading microorganisms prevail. In many studies on substrate inhibition effects in wastewater treatment processes, phenolic compounds, known to be major pollutants in industrial wastewater, ${ }^{222}$ have been used as model compounds. Phenolic compounds are toxic or inhibitory even to acclimatized biomass at relatively low concentrations. ${ }^{221}$ Watanabe et al. ${ }^{221,222}$ showed that phenol loads exceeding $1.5 \mathrm{~g} \mathrm{~L}^{-1} \mathrm{~d}^{-1}$ caused a breakdown of an activated sludge process within one week due to an outbreak of non-flocculating catabolic populations and subsequent washout of biomass. Galil et al. ${ }^{74}$ also observed an increase in turbidity upon shock loads of phenol, indicating deflocculation. Deflocculation of activated sludge also occurs when microbial activity 
is inhibited by, for example, anaerobic conditions, addition of metabolic inhibitors, starvation, and temperature changes. ${ }^{224,225}$ Schwartz-Mittelmann and Galil ${ }^{181}$ investigated the biological mechanisms involved in bioflocculation disturbances caused by phenol and found that deterioration of settling characteristics occurred, especially under growth conditions, due to cell lysis, lowering of hydrophobicity, and unbinding of exocellular biopolymers resulting in small sludge particles. This is in agreement with the observation by Sawada and Nakamura ${ }^{178}$ that stationary cells were more resistant to toxic compounds than exponential growing cells. Hydrophobic toxic compounds like phenol may cause membrane damage, thereby impairing biological functions that depend on the intact state of membranes. ${ }^{181}$ Toxicity may also increase with an increased period of exposure to the toxicant as found for linear alkylbenzene sulfonates (LAS) in anaerobic digestion. ${ }^{103,156}$ These LAS, widely used as detergents, inhibit anaerobic digestion via an immediate inhibition and a subsequent further decrease of activity. ${ }^{156}$ Similar effects of increased toxicity at longer exposure periods have been reported for aromatic compounds toward pure cultures of methanogens. ${ }^{168}$

\section{INFLUENT CHARACTERIZATION AND MONITORING FOR PREVENTION OF ORGANIC AND/OR TOXIC SHOCK LOADS}

For the treatment of industrial wastewater containing inhibitory compounds, characterization of the wastewater is important to assess suitable (pre)treatment and/or loading rates in order to avoid serious plant upsets. Assessment of toxicity with tests employing Vibrio fischeri, ${ }^{90}$ Daphnia Magna, ${ }^{190}$ or algae ${ }^{75}$ is useful when applied for regulatory purposes to protect receiving water bodies from toxicity due to effluent discharge from wastewater treatment plants. However, to evaluate any potential toxicity in the influent to a biological wastewater treatment plant, the use of commercially available toxicity tests employing $V$. fischeri does not yield relevant information, as the used organism originates from the marine environment and is generally known to be too sensitive to give representative effects of toxicants on activated sludge. ${ }^{41,79}$ Gutierrez et al. ${ }^{79}$ compared the toxicity tests using $V$. fischeri and $\mathrm{O}_{2}$ uptake inhibition using activated sludge and found that the toxicity assessed was generally much lower in the latter test. Other toxicity tests reported with relevance to wastewater treatment plants are:

- ATP luminescence, a measure of active biomass, enzyme inhibition ${ }^{41}$;

- enzyme inhibition targeting L-alanine-aminopeptidase ${ }^{41}$ or dehydrogenase activity $^{23,187}$; and 
- nitrification inhibition, as nitrification is the most critical step in nitrogen removal, and nitrifyers are often more strongly inhibited than heterotrophic organisms by toxic compounds. ${ }^{94,228}$

Obviously, the best and most representative results would be obtained if the sludge treating the wastewater that is being characterized is used in the inhibition assay. ${ }^{79,113,228}$

To protect industrial wastewater treatment plants from toxic shocks, the use of online toxicity analysis is preferred. However, most toxicity tests are offline analysis and cannot measure real-time toxicity in the influent. Kungolos ${ }^{113}$ proposed the use of online respirometry for the evaluation of toxic properties of industrial wastewater. Continuous monitoring of combined industrial discharges, carried out for a period of six months, revealed the absence of a correlation between toxicity and organic load. ${ }^{113}$ This indicates that simply monitoring of organic load is not helpful in determining the toxicity. Combined and accurate online determination of both organic load and toxicity not only prevents malfunctioning of wastewater treatment facilities, but would probably enhance the treatment efficiency and throughput. Furthermore, early warning systems save substantial amounts of time and money spent on pilot-scale tests to evaluate the cause of diminished treatment efficiency. ${ }^{105}$ Measurement of nitrification inhibition can also be done using respirometry. ${ }^{107} \mathrm{Koh}$ and Ellis ${ }^{105}$ developed a protocol for rapid detection and evaluation of the inhibitory characteristics of influent wastewaters that included assessments of carbon oxidation, nitrification, and anaerobic inhibitions to provide the necessary sensitivity of the biosensors.

Luminescence-based microbial assays for toxicity are useful to detect the presence of bacterial toxicants and can be used as a screening system for a wide range of toxicants. ${ }^{22}$ Bioluminescence lends itself well for automation, as light itself is easy to measure, allowing for the rapid processing of toxicity data. ${ }^{184}$ The most widely used bioluminescence assay employs $V$. fischeri, as mentioned earlier, but due to its salt requirements and narrow $\mathrm{pH}$ range for growth makes this unsuitable for online automation of toxicity screening. Furthermore, the $\mathrm{pH}$ and salinity using $V$. fischeri toxicity tests may differ significantly from the in situ conditions, which could inadvertently alter the toxicant properties. ${ }^{226}$ The use of genetically modified microorganisms for toxicity screening has been reported that carry the lux operon from Photorbabdus luminescens, ${ }^{226,227} \mathrm{~V}$. fischeri, ${ }^{119}$ or the luciferase gene from a firefly. ${ }^{184}$ Lux genes encode for luciferase and aldehyde production, indicating that luminescence is a result of the occurring respiratory reactions. ${ }^{22}$ Brown et al. ${ }^{24}$ reported that a genetically modified Pseudomonas fluorescens was more sensitive than respirometry, although it demonstrated the same order of toxicity for cadmium and pentachlorophenol (PCP) in their experiments. Wiles et al. ${ }^{227}$ used several indigenous isolates from the wastewater 
plant, with different phenol tolerance, which can provide time to implement actions to deal with high toxic loads. These microorganisms could be used in handheld luminometers for ex situ toxicity monitoring or even as online in situ monitoring system within multiple treatment compartments. ${ }^{227}$ Wiles et al. ${ }^{227}$ suggest that the use of a disarmed transposon to locate the lux operon on the chromosome of the bacteria provide genetic and phenotypic stability, which limits the possibility of horizontal gene transfer to a very low frequency when the biosensor would be used in situ. Nevertheless, the use of genetically modified microorganisms in open wastewater treatment systems may be unacceptable for the unpredictable effects they might cause in the environment. Prevention of the spreading of genetically modified organisms into the environment could be obtained by employing them in small membrane units, in continuous contact with the wastewater influent, but preventing their presence in the effluent. Genetically modified microorganisms with bioluminescence for toxicity assessment have been developed for a wide range of potential toxic compounds, including herbicides, ${ }^{184}$ surfactants, ${ }^{119}$ volatile organics, ${ }^{22}$ polychlorinated biphenyls ${ }^{118}$ phenols, ${ }^{229}$ and metals and metalloids. ${ }^{191}$

\section{MODELING AND SIMULATION AS TOOLS FOR OPTIMIZATION OF INDUSTRIAL WASTEWATER TREATMENT PLANTS}

Modeling of transients to improve the understanding and characterization of the response to environmental changes in industrial wastewater influent characteristics is a difficult and complex problem due to the wide range and large variations of perturbations. ${ }^{13}$ In short time spans (hours to days), ratios and other model parameters may change drastically. ${ }^{28}$ Uncertainties in lab analyses and online measurements (e.g., flow, dissolved oxygen, and ammonium concentration) further complicate the modeling exercise. ${ }^{28}$ Bury et al. ${ }^{28}$ further mention that variable features of the employed wastewater treatment facilities (e.g., different reactor configurations, high operating temperatures, and high salinity) often require case-specific modeling. Whereas steady-state models employ equilibrium conditions for simplification, these equilibrium conditions are not valid under transient state conditions.

Ferreira Jorge and Livingston ${ }^{67}$ attempted to model the degradation of monochlorobenzene and 1,2-dichloroethane by a consortium of two specific degraders in a continuous stirred tank reactor, with special emphasis on the effluent concentrations upon substrate changes. Although the model described the accumulation of a newly introduced compound qualitatively well, the accumulation was considerably overestimated due to underestimated biomass concentrations after a starvation period. This suggests that the kinetics used in the model, which were obtained from biokinetic experiments in pure cultures, did not represent the actual situation well. 
This emphasizes the necessity of determining and validating appropriate kinetics for multiple pollutants elimination. ${ }^{47}$

Goodall and Peretti ${ }^{76}$ also developed a model describing the transient activity of a mixed immobilized culture of Comamonas spp. JS46 and JS47 growing preferentially on meta- and para-nitrobenzoate, respectively. Alternatively, one of the species in the mixed culture was starved, and upon resuming feeding of the substrate, its consumption was assumed to depend on the amount of active immobilized biomass as well as on the activity of the key pathway. ${ }^{76}$ However, as detailed mechanistic pathway information was not available, an often encountered phenomenon, respirometry was used to characterize both the amount and activity of the involved organisms. ${ }^{76}$ In their model, Goodall and Peretti ${ }^{76}$ introduced specific parameters for the biomass activity and for the pathway activity and predicted the transient behavior of the immobilized cell reactor successfully. Nevertheless, the quantitative response was underpredicted, probably as a result of model simplifications. ${ }^{76}$

Despite the difficulties in modeling transients in wastewater influent characteristics, model-based optimization of industrial wastewater treatment facilities was proposed as an efficient and cost-reducing way to ensure ful-

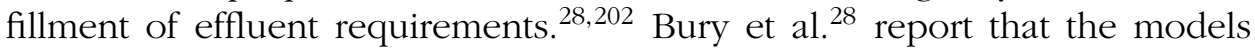
they developed provided consistent descriptions of individual plants, operator and engineer training, more effective and risk-free experimentation, and optimization of performance. A complication in the modeling of industrial wastewater treatment plants is the occurrence of compounds that are normally not present in significant amounts in domestic wastewater, for which existing models, such as the Activated Sludge Models numbers 1-3 (ASM1-3) ${ }^{83}$ have to be extended to cope with these specific components. ${ }^{202}$

Successful large-scale dynamic simulation is a combination of factors, such as good biokinetic models, good hydraulic, reactor and clarifier models, good control models, good ancillary models, data analysis tools, good numerics, and customization. ${ }^{28}$ Their application potential ranges from process trouble-shooting to optimization and control. Bury et al. ${ }^{28}$ described several case studies in which dynamic modeling and simulation was successfully applied for trouble shooting in the wastewater treatment facilities operated by DOW chemicals. ASM1, used as a base kinetic framework, was extended with various parameters depending on each specific case under investigation. ${ }^{28}$ They have successfully used dynamic modeling for identification of a nitrification failure, optimization of a biosolids thickener, optimization of the performance of an alternately overloaded and underloaded process, maintaining biomass populations for degradation of trace and inhibitory compounds through proper reactor design, and the control of nitrification and denitrification via dissolved oxygen levels as a function of the incoming COD:N ratio improving clarifier performance, which was previously hampered by the occurrence of floating sludge due to denitrification. ${ }^{28}$ 
Van Hulle and Vanrolleghem ${ }^{202}$ investigated a dynamic modeling approach for an industrial facility characterized by a varying production schedule that discharges to an existing wastewater treatment plant. ASM1 was extended with components that take into account specific substrates present in the wastewater, inhibition kinetics of specific substrates, and temperature dependency. Furthermore, as the influent composition of many industrial wastewaters differs greatly from domestic wastewater, it was not possible to use the default values of the biological parameters in ASM1, and therefore a recently developed calibration protocol ${ }^{170}$ was used to perform a thorough biological characterization. ${ }^{202}$ After successful calibration and validation, the model showed that a $20 \%$ reduction of the degradable COD concentration in the effluent could be achieved by operating the activated sludge treatment in series instead of in parallel. ${ }^{202}$

Dynamic simulations have also been used to evaluate the effect of different production schedules from multiple production facilities on the fulfillment of wastewater effluent quality requirements. ${ }^{202}$ In many batch-wise producing industries, the yearly production can be obtained through varying the production of specific products in time, which may drastically affect the treatability of the wastewater when wastewater from multiple production units is discharged to a combined treatment facility. ${ }^{202}$ Furthermore, such models could be used to predict the impact of a future production facility on the overall wastewater treatment efficiency. ${ }^{202}$ Although this so called waste design has to be combined with economic considerations (e.g., market demand and production costs), waste design itself could be an economic consideration via reduced effluent fines. ${ }^{202}$

Despite the demonstrated potential of dynamic models and simulations for the optimization of full-scale treatment facilities, substantial work remains by plant engineers and operators to implement these for real-time use. Bury et al. ${ }^{28}$ state that the use of dynamic simulations to improve treatment performance will remain largely untapped until dynamic state estimation and data reconciliation are incorporated into simulation packages for use in developing the online simulations. For a successful introduction of dynamic simulations into the control room of wastewater treatment facilities, such simulations must further be able to auto-calibrate and auto-validate based on recent and current operating conditions and data from the wastewater treatment plant. ${ }^{28}$ For this, simulation tools have to be developed.

\section{BIOREACTOR CONSIDERATIONS FOR THE TREATMENT OF HIGHLY VARIABLE WASTEWATERS}

A prerequisite in order to enable bioreactors to deal with transient conditions, such as $\mathrm{pH}$ shocks, toxic loads of certain compounds, organic loading 
shocks, or SAP, is a sufficiently large and active community of microorganisms capable of degrading the organic matter present in these waste streams. Therefore, bioreactor design is one of the key aspects. For the treatment of highly variable wastewaters, the use of suspended or flocculent biomass reactors, such as the conventional activated sludge systems, seems less appropriate. Such reactors are more susceptible for washout of biomass upon shocks of $\mathrm{pH}$ or toxic concentrations and will also not be able to handle sudden increases in the organic load due to the relatively high food to microorganisms $(\mathrm{F} / \mathrm{M})$ ratio at which these reactors are operated. Furthermore, due to the fact that short SRT in this type of reactors (i.e., typical SRT of conventional activated sludge plant) is in the range of 5 to 15 days, ${ }^{51}$ adaptation to toxic and/or SAP would be seriously hampered.

A stable microbial community is more likely to develop in immobilized biomass reactors, such as the immobilized bed biofilm reactors (see Figure 2A), moving bed biofilm reactors (see Figure 2B), biotrickling filters (see Figure 2C), rotating biological contactors (see Figure 2D), and aerobic or anaerobic granular sludge reactors. ${ }^{17,164,209}$ Prieto et al. ${ }^{173}$ reported that immobilized cells of Rhodococcus erythropolis degraded phenol faster and with shorter lag phase compared with suspended cells of the same strain. Immobilized cells could completely degrade $11 \mathrm{~kg} \mathrm{~m}^{-3} \mathrm{~d}^{-1}$, which was about 8.5 times more than the maximum rate calculated for suspended cultures. ${ }^{173}$ Immobilized biomass has shown a better response to organic shock loads and toxic pollutants, and in many cases, reactors employing immobilized biomass completely recover their performance after deleterious occurrences. ${ }^{5}$ Furthermore, immobilized microorganisms have been found to remain more active in starvation periods and revealed a shorter lag phase after introduction of a degradable compound. ${ }^{68,162}$ This has been attributed to a better biomass retention and higher cell density in immobilized biomass reactors, ${ }^{163,169}$ which is particularly important for slow growing organisms that perform the biodegradation of xenobiotic compounds. A high biomass density and retention is for the same reason expected to enhance the performance of bioreactors treating SAP. Furthermore, a higher biomass density results in low $\mathrm{F} / \mathrm{M}$ ratios, and thus are operated far from the maximum metabolic capacity of the microorganisms present. This suggests that sudden increases in organic load could be easier handled than in suspended biomass systems. Moreover, a high biomass density and low $\mathrm{F} / \mathrm{M}$ ratio results in low biomass yields and potentially extreme long SRT (e.g., exceeding 100 days in biotrickling filters and rotating biological contactors), ${ }^{51}$ which is highly advantageous for the development of communities for the biodegradation of xenobiotics. Moreover, immobilized cells can better withstand changes in environmental conditions, such as temperature, $\mathrm{pH}$, and toxic concentrations, ${ }^{120}$ due to the development of $\mathrm{pH}$ and substrate gradients, preventing a large part of the microbial community to experience the detrimental conditions encountered in the bulk medium. Such 

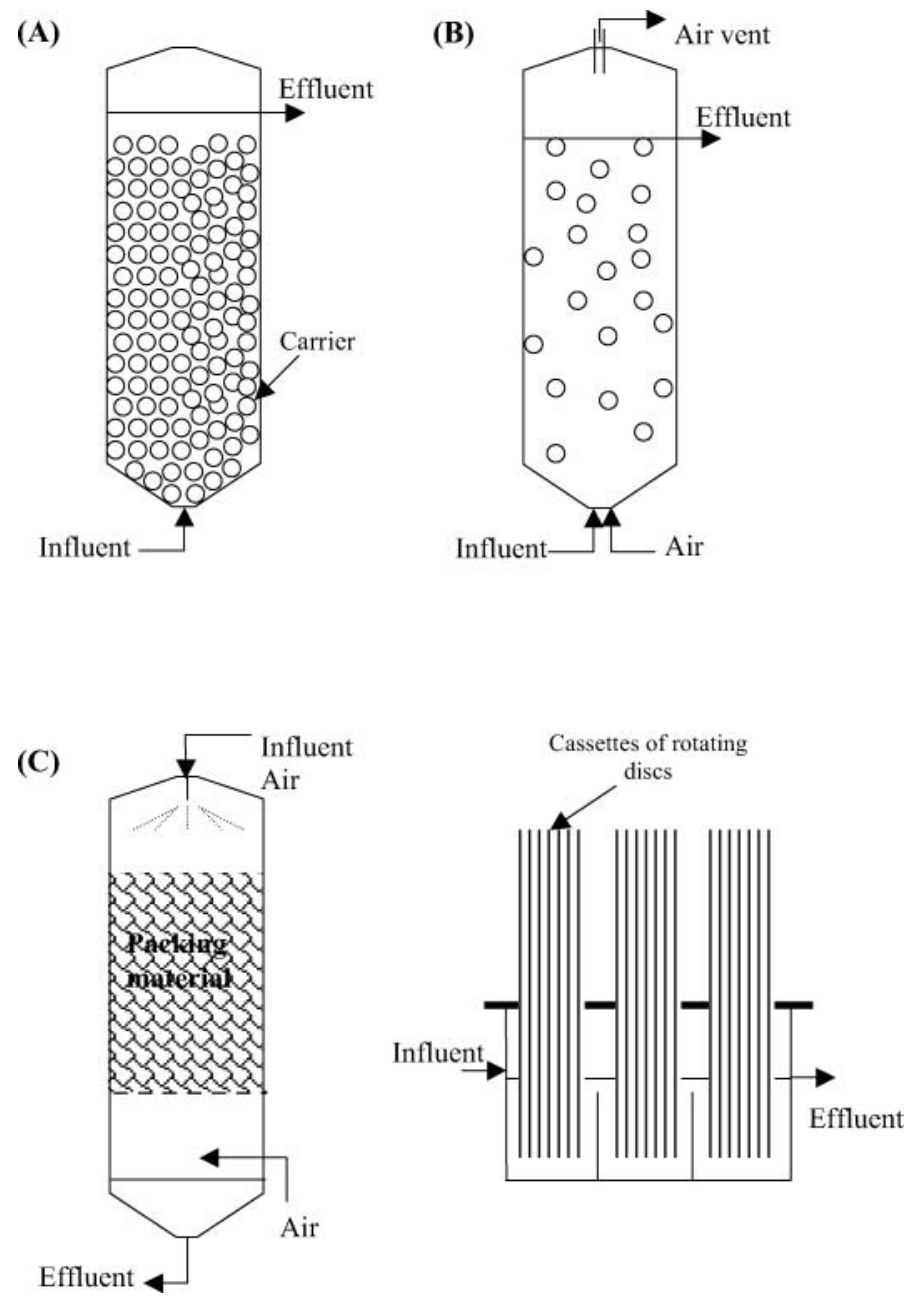

FIGURE 2. Schematic representation of typical biofilm reactors: a) immobilized bed biofilm reactor (anaerobic or equipped with internal oxygen providing membrane); b) moving bed biofilm reactor; c) biotrickling filter; and d) rotating biological contactor.

concentration gradients have also been reported to be beneficial for the protection of toxicity from sulfide ${ }^{108,124}$ and long chain fatty acids ${ }^{86}$ in anaerobic granular sludge. For these reasons, bioreactors employing immobilized biomass have significant better characteristics to handle environmental stress such as pH shocks, hydraulic, and/or organic shock loads; wastewaters containing toxic compounds; and wastewaters containing sequential alternating pollutant.

Besides bioreactors employing biofilms for biomass retention, membrane bioreactors (MBR) offer a complete retention of biomass and thus will show many similar advantages as biofilm reactors over suspended or 
flocculent growth bioreactors for the treatment of industrial wastewaters. Due to recent technical innovations and significant cost reductions of especially the employed membranes, the applicability of MBR technology for wastewater treatment of both industrial and domestic has sharply increased. ${ }^{201}$ MBR are characterized by high biomass concentrations, low sludge production, low F/M ratios, and long SRT, which are all beneficial for the treatment of highly variable industrial wastewaters. Unlike in biofilm reactors, the biomass will be mainly present in the suspended or flocculent form, which likely does not lead to the formation of significant $\mathrm{pH}$ or substrate gradients into the biomass. The latter may negatively affect the reactor performance in the treatment of toxic compounds, as the floc size has been found to affect respiration inhibition by soluble toxicants. ${ }^{82}$ They reported that the flocs from a MBR, which were on average $41 \%$ smaller than those from an activated sludge plant, were 2 and 1.25 times more sensitive to toxic shocks of cadmium and 2,4-dinitrophenol, respectively.

MBRs exist in different configurations (see Figure 3). The most simple configuration is based on a conventional activated sludge plant in which the sedimentation tanks are replaced by membrane filtration, either internally in the bioreactor or externally in separated tanks (see Figures 3A and 3B). ${ }^{89,201}$ In another configuration, the membrane separates the biomedium from the wastewater by an extractive membrane (see Figure 3C), that is, the pollutants diffuse from the wastewater through the membrane into a biomedium containing microorganisms. ${ }^{134-136}$ Because the biomass is physically separated from the wastewater, extreme environmental characteristics of the wastewater such as high $\mathrm{pH}$ and salinity principally do not affect the microbial activity in the biomedium. ${ }^{129,135,136}$ Furthermore, this configuration is also highly suitable for the treatment of poorly water-soluble ${ }^{186}$ and volatile ${ }^{72}$ organic compounds due to the formation of a biofilm on the membrane surface.

In addition to the conventional biofilm reactors and MBRs for biomass retention mentioned previously, the combination of several concepts into so-called hybrid systems has been investigated. Hybrid systems may combine positive aspects of suspended (e.g., improved mass transfer) and immobilized growth systems (e.g., biomass concentration, retention, and age). Al-Sharekh and Hamoda ${ }^{3}$ studied this principle for treatment of municipal wastewater in an aerated compartmentalized tank reactor with submerged fixed-film bioreactor on ceramic surfaces. They report that the process can handle wide variations in hydraulic and organic loading rates due to the high biomass concentration and substrate utilization rate. However, the suspended biomass concentration in their experiments was maximally about $2.4 \mathrm{~g} \mathrm{~L}^{-1}$ and only $10-20 \%$ of the total biomass present in the reactor was present as a biofilm on the carrier. Nevertheless, the attached biomass could play a role in the stabilization of the performance during shock loads. Yeom and $\mathrm{YoO}^{239}$ proposed the use of a bubble column reactor combined with 


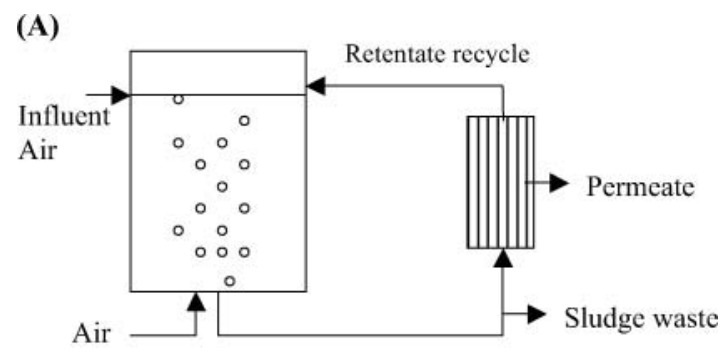

(B)
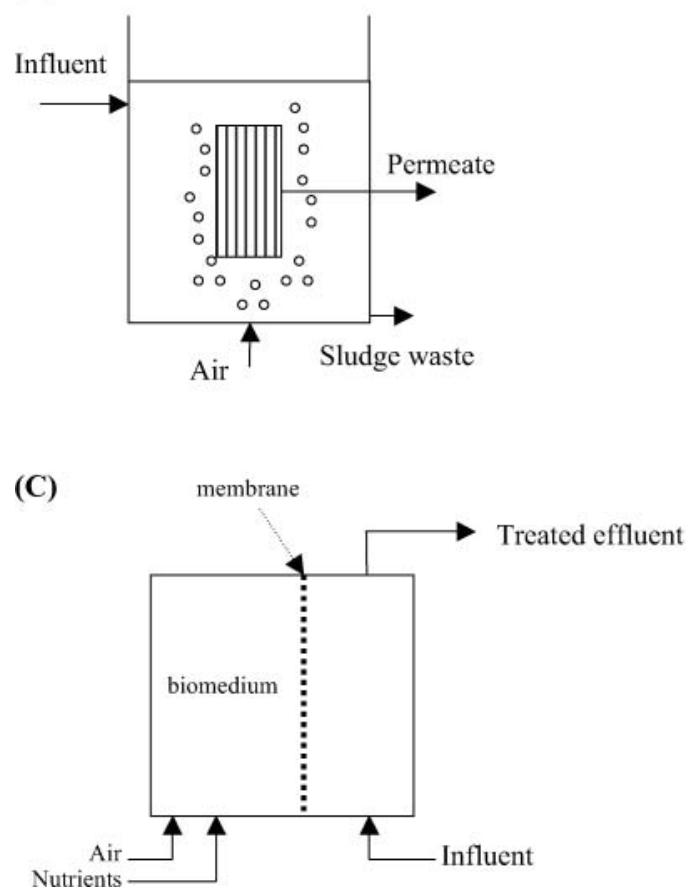

FIGURE 3. Concepts of different types of membrane bioreactors (MBR) used in wastewater treatment: a) sidestream or external MBR; b) immersed MBR; and c) extractive MBR.

a biofilter section for the treatment of volatile organic compounds containing wastewater, which was suggested to handle shock loads by increasing the aeration and sharing the VOC between both the aqueous reactor and the biofilter. Combinations of immobilized and suspended growth concepts have been shown to efficiently remove $90 \mathrm{mg} \mathrm{L}^{-1}$ nitrobenzene in a biotrickling filter followed by an activated sludge system ${ }^{140}$ and capable of handling organic shock loads of $180 \mathrm{mg} \mathrm{L}^{-1}$. The same system was previously used for the treatment of $100 \mathrm{mg} \mathrm{L}^{-1}$ trichloroethylene (TCE) with a maximal removal efficiency of $99.99 \% .{ }^{146}$ In this study, during a shock load of twice the 
original TCE concentration, the system was capable of achieving a removal efficiency of $95 \%$.

\section{GROWTH IN BIOFILMS AND PROTECTION AGAINST TOXIC COMPOUNDS: ROLE OF EXTRACELLULAR POLYMERIC SUBSTANCES (EPS)}

Growth in biofilms renders microbial cells several competitive advantages over planktonic growth as previously described, especially for the treatment of complex and potentially toxic wastewaters. Although the metabolic activities of individual microorganisms within biofilms are not as high as for planktonic cells due to existing substrate gradients, these substrate gradients may result in a drastically reduced overall toxicity and significantly improve treatment efficiency. Dense biofilms may appear on top of an inert surface (e.g., carrier material, reactor walls, or as auto-immobilized biomass granules, as found in aerobic ${ }^{17}$ and anaerobic ${ }^{179}$ granular sludge reactors). In addition to microbial cells, a key component of biofilms is referred to as extracellular polymeric substances (EPS), which actually contains many different molecules.

EPS is usually divided in bound and soluble EPS: bound EPS includes microbially produced bound polymers, lysis, and hydrolysis products as well as absorbed or attached matter, whereas soluble EPS contains microbially produced soluble polymers, hydrolysis products, and organic molecules originating from cell lysis. ${ }^{40}$ Soluble EPS and the also often-encountered term soluble microbial products are actually the same according to the unified theory of Laspidou and Rittmann. ${ }^{117}$ They define soluble EPS as biodegradable and actively secreted, whereas bound EPS are polymers bound to active and inert biomass or molecules resulting from cell lysis.

Important functions of EPS in biofilms are adhesion to surfaces, aggregation of bacterial cells, formation of a protective barrier, retention of water, and sorption of exogenous organic compounds. ${ }^{40,117}$ Davies et al. ${ }^{42}$ reported that not the EPS content, but rather the shape of the biofilm acts as a protective barrier against biocides and aids in the retention of water. Cell-to cell communications in a biofilm composed of cells of Pseudomonas aeruginosa via a diffusible extracellular signal, $N$-(3-oxododecanoyl)-L-homoserine lactone $\left(3 \mathrm{OC}_{12}-\mathrm{HSL}\right)$, resulted in the formation of a thick biofilm composed of microcolonies of groups of cells separated by water channels, whereas mutant strains that did not produce this extracellular signal formed thin and densely packed flat sheet biofilms. ${ }^{42}$ Despite the fact that the EPS levels of both biofilms were similar, the wild type strain was unaffected by a treatment with $0.2 \%$ sodium dodecyl sulfate, whereas the mutant detached and dispersed within five minutes. ${ }^{42}$ Brown et al. ${ }^{25}$ found a higher 
povidone-iodine resistance in biofilms of $P$. aeruginosa compared to planktonic cells, despite the fact that EPS levels were similar, from which they concluded that the higher resistance was due to a protective layering within the EPS matrix. Furthermore, it has been found that the type and amount of EPS produced by microorganisms depend on substrate and environmental conditions. ${ }^{6,7,12,71,99,100,117}$ Excessive production of EPS in an UASB reactor upon the change from starch to sucrose as carbon source resulted in a slower decrease of gas from the anaerobic granules and in flotation and washout of granules. $^{73}$

\section{EPS AND BIOSORPTION IN BIOFILM REACTORS}

Growth in biofilms decreases the toxicity of many compounds due to its layered structure, but also due to the specific binding of molecules, and thereby decreasing their concentration in the aqueous phase. In the case of a slowly degradable substrate, which is often the case for many inhibitory compounds, absorption in the biofilm can enhance its degradation potential considerably. The activity of specific degraders developed within the biofilm could determine the desorption of the toxic substrate. In the case of incidental occurrence of a specific toxic compound, this biosorption to the biofilm results in longer availability of substrate and decreased length of starvation periods. The latter could be highly beneficial in the case of regular discontinuous occurrence of specific toxic compounds.

Although cells themselves may bind cationic pollutants due to the overall negative charge of the cell wall, the biosorption capacity of biofilms is generally thought to be related to the amount and type of EPS. Due to the presence of anionic groups, such as carboxyl, phosphoryl, and sulfate groups, EPS has a net negative charge and therefore a potential for cation exchange. ${ }^{40}$ Nevertheless, as a result of its heterogeneous character, biosorption is not limited to cationic compounds only. Flemming ${ }^{71}$ suggested that also sorption of anions must occur due to the presence of positive charges within the EPS (e.g., on amino groups in sugars, sugar acids, and proteins that for a large part make up the EPS). Accumulation of sulfate, phosphate, and nitrates in biofilms has been observed. ${ }^{71}$ Furthermore, Wolfaardt et al. ${ }^{232}$ showed that both polyanionic and cationic dextrans bound irreversibly to specific areas of the biofilm matrix, demonstrating that both positively and negatively charged microzones exist in biofilms. Flemming ${ }^{71}$ further suggested that apolar and hydrophobic molecules may be sorbed by EPS, as sorption of hydrophobic molecules can be compared to the process of adhesion of microorganisms in biofilms on hydrophobic surfaces. Flemming ${ }^{71}$ suggest that apolar regions of proteins provide suitable sites for apolar molecules to bind. Accumulation of the herbicide diclofop methyl within EPS was observed by Wolfaardt et al. ${ }^{231}$ Finlayson et al. ${ }^{70}$ found significant biosorption by activated sludge flocs for 
1,2 dichloroethane, 1,1,2 trichloroethane, phenanthrene, and pyrene. Furthermore, biosorption of high molecular weight chlorinated organic compounds on sewage sludge flocs, ${ }^{238}$ of PCP in a MBR, ${ }^{212}$ and of humic and fulvic substances on sewage sludge flocs ${ }^{62}$ were reported.

In bioreactors with dense and immobilized biomass, the EPS content and thus the potential biosorption capacity may be significantly increased. Davies $^{43}$ reported that cells produce up to 19 times more EPS when forming biofilms, as compared to planktonic cells. In another study, Wang et al. ${ }^{220}$ showed that the EPS content of aerobic granules from a SBR contained EPS concentrations of $47 \mathrm{mg}$ (g MLSS) $^{-1}$, whereas the activated sludge inoculum revealed an EPS concentration of only $17 \mathrm{mg}(\mathrm{g} \text { MLSS })^{-1}$. Biosorption of heavy metals on EPS has been studied extensively. ${ }^{40,71,78,171,243}$ In particular, the application of heavy metal remediation using aerobic granular sludge has been recently proposed for the removal of cerium, ${ }^{244}$ cadmiun, ${ }^{130}$ copper, and zinc, ${ }^{131,237}$ due to the biosorption capacity and much higher density and settleability of aerobic granuler sludge compared to conventional bioflocs.

Biosorption on anaerobic sludge also occurs, as shown by Kennedy et al., ${ }^{101}$ for a range of chlorophenols. However, by comparing their results with literature reports of biosorption on activated sludge, they concluded that the biosorption of these compounds onto anaerobic granular sludge was drastically lower (i.e., respectively 10- and 20-fold) compared to dead and alive activated sludge. ${ }^{101}$ Factors they mention that might have negatively influenced the biosorption of these hydrophobic compounds are the higher test temperature (i.e., $35^{\circ} \mathrm{C}$ versus $20^{\circ} \mathrm{C}$ ) and the qualitative difference of the cell membrane lipids from aerobic (bacteria) and anaerobic microorganisms (bacteria and archaea), which might have different sorptive properties. ${ }^{101,102}$ Furthermore, no significant differences were found in biosorption capacity of dispersed and granular anaerobic sludges, indicating that an increased surface area after dispersing anaerobic granules did not lead to higher biosorption. ${ }^{102}$ Other factors that may affect biosorption by anaerobic sludge are the reported lower EPS concentration compared with activated sludge and its high sludge age, which results in higher protein-tosaccharide ratios that consequently lower the overall negative charge and thus decrease the cation exchange capacity. ${ }^{12,128,152}$

\section{ENHANCED ADSORPTION IN BIOREACTORS}

Adsorption processes are beneficial in the treatment of inhibitory pollutants as discussed in the previous section. Nevertheless, the biosorption capacity in biofilms is rather limited. In the case of treatment of toxic wastewaters with relatively high and/or variable concentrations, the use of adsorbents with a high adsorption capacity is preferred. Activated carbon has a high adsorption capacity for many inhibitory pollutants. 
Furthermore, granular activated carbon has a high surface area and porous structure, which facilitates the formation of biofilms. ${ }^{1}$ Its use as support material in carrier-assisted biofilm reactors has been successfully demonstrated for the treatment of wastewaters containing many different toxic compounds (e.g., containing 2-fluorobenzoate ${ }^{58}$; fluorobenzene ${ }^{31,32}$; methyl tertbutyl ether; 4 -chlorophenol ${ }^{30}$; benzene, toluene, ethylbenzene, and xylene $(\mathrm{BTEX})^{174} ; \mathrm{PCP}^{104}$; phenol, p-nitrophenol, and phenanthrene ${ }^{1}$; and atrazine and simazine ${ }^{64}$ ).

Activated carbon enhances the buffer capacity of a biological treatment system due to adsorption of the toxic compounds present, thereby decreasing the toxicity toward the microorganisms. Mensah and Forster ${ }^{144}$ investigated the toxicity of wastewater from a detergent manufacturing process and concluded that a combination of activated carbon and anaerobic treatment was required to overcome toxicity problems at concentrations of $10 \mathrm{~mL} \mathrm{~L}^{-1}$ detergent, which was the maximally encountered detergent concentration in these specific wastewaters. In the absence of activated carbon, concentrations of $2 \mathrm{~mL} \mathrm{~L}^{-1}$ caused a pronounced deterioration of the reactor performance. ${ }^{144}$ Köhler et al. ${ }^{106}$ observed for wastewater from fluorescent whitening agent production that the adsorption onto activated carbon decreased the toxicity towards algae by $40 \%$ with limited total organic carbon (TOC) removal.

The buffer aspect of activated carbon also enhances the stability of a biofilm that is used to treat waste streams containing SAP, ${ }^{58}$ as in periods that a certain target compound is not present in the wastewater influent, low concentrations are still available for prolonged periods due to desorption from the activated carbon. ${ }^{33,54}$ Such prolonged periods of availability of a specific compound decreases the starvation periods and maintains the biomass metabolically active. Emanuelsson et al. ${ }^{58}$ compared biofilm reactors containing granular activated carbon (GAC) and expanded clay as biofilm carrier, and observed that after a starvation period, no 2-fluorobenzoate fed could be detected in the effluent of the GAC reactor, whereas with the expanded clay reactor 15 days were required to achieve complete elimination of 2-fluorobenzoate from the effluent. However, the biological elimination capacity (i.e., the biodegraded amount of 2-fluorobenzoate) was found to be drastically higher in expanded clay reactors compared to GAC reactors, despite the incidental occurrence of 2-fluorobenzoate in the effluent in the former. ${ }^{59}$ Nevertheless, the use of activated carbon is highly interesting in the treatment of highly variable inhibitory wastewaters.

Hybrid systems that combine the adsorption of toxic compounds within a biological system could result in more stable operation of the biological mineralization process. The use of activated carbon in fixed bed reactors potentially leads to clogging of the bed when the organic matter content of the wastewater is high.55,166 Therefore, for high strength wastewaters containing inhibitory compounds, the combination of activated carbon with high 
rate reactor types could overcome the problems related to clogging. Suidan et al. ${ }^{188}$ demonstrated the treatment of high strength synthetic industrial wastewater containing acetate, phenol, and 2-chlorophenol in an anaerobic fluidized bed GAC reactor. The GAC was instrumental in controlling the build up of 2-chlorophenol in the reactor upon large pulse inputs. ${ }^{188}$ Thuy and Visvanathan ${ }^{196}$ proposed the use of GAC in a MBR for the treatment of high-strength phenolic wastewaters. They suggested that the GAC-MBR was more stable; however, significant differences were not evident from their results comparing a GAC-MBR with a conventional MBR. This was likely due to the relative low adsorption capacity of the used GAC for phenol (i.e., with an adsorption capacity of only $12.3 \mathrm{mg} \mathrm{g}^{-1}$ and a GAC concentration of $5 \mathrm{~g}$ $\mathrm{L}^{-1}$ in the reactor, the contribution of adsorption is rather insignificant at a phenol load of 1.8 to $5.76 \mathrm{~g} \mathrm{~L}^{-1} \mathrm{~d}^{-1}$ ). Furthermore, the addition of GAC increased the viscosity of the aqueous solution due to an increased amount of dispersed microorganisms compared to the conventional MBR, leading to earlier fouling of the membrane. ${ }^{196}$ Probably, the latter is also affected by the low adsorption capacity of the used GAC for phenol, as in case of high adsorption rates, the microorganisms will most likely predominantly occur in a biofilm on the GAC, which is assumed to improve the filterability of the membrane due to the presence of relatively large particles in the reactor liquid. In contrast, Ehrhardt and Rehm ${ }^{54}$ reported a much better adsorption of phenol onto granulated activated carbon (i.e., phenol adsorption to about half of the weight of the activated carbon), and Mörsen and Rehm ${ }^{155}$ even reported an adsorption capacity of the activated carbon used in their study of $0.7 \mathrm{~g}$ phenol per $\mathrm{g}$ activated carbon. Therefore, the use of activated carbon with a high adsorption capacity in bioreactors treating slowly degradable or toxic substances is potentially interesting. The beneficial effect of powdered activated carbon (PAC) has been shown in a MBR for the treatment of tannery wastewater. ${ }^{157}$ Although no improvement in COD removal efficiency was observed, membrane fouling was significantly reduced. ${ }^{157}$ Furthermore, Seo et al. ${ }^{183}$ used PAC in a MBR for treatment of a secondary effluent of a domestic wastewater treatment plant for water reclamation and obtained effluent COD and TOC of 5 and $2 \mathrm{mg} \mathrm{L}^{-1}$, respectively, at influent concentrations ranging from 25 to $80 \mathrm{mg}^{\mathrm{COD} \mathrm{L}} \mathrm{L}^{-1}$. They reported that small molecules were mostly removed by adsorption and biodegradation, whereas larger molecules were rejected at the PAC cake layer on the membrane surface and gradually degraded after extended contact. The positive effect of increased particle size on the filterability in MBRs has also been reported: in a MBR inoculated with granular aerobic sludge, the membrane permeability in a 60 days experiment was 50\% higher than in a MBR inoculated with activated sludge. ${ }^{127}$ This demonstrates the potential advantage of growth in biofilms inside a MBR for control of biofouling, although the stability of aerobic granules in a MBR is disputable, as there is little physiological need for granulation inside a MBR and granules are likely to disintegrate with time. 
The combination of adsorption and biodegradation has been successfully demonstrated in an anaerobic column reactor for the removal of branched chain fatty acids, neopentonoic acid, and 2-ethylhexanoic acid used for pharmaceutical synthesis and usually persistent in conventional activated sludge systems. ${ }^{36}$ The combination of an adsorption and biological process is not merely beneficial for the biological process, but also for the adsorption process itself (i.e., bioregeneration of the activated carbon results in renewal of its adsorptive capacity). However, despite the fact that microorganisms can extend the operational period of the activated carbon considerably, the adsorption capacity slowly deteriorates, and activated carbon needs to be replaced with time. ${ }^{30,33}$

Besides the use of activated carbon, the use of immiscible and nonbiodegradable organic solvents has been reported for the protection of the biomass against inhibitory concentrations of phenol $^{38}$ and benzene, toluene, and $p$-xylene. ${ }^{39}$ In these processes, the relatively hydrophobic pollutants are absorbed in the organic solvent, which is subsequently released to the biomedium at low concentrations. The use of such organic solvents has been studied for the clean-up of simulated soil spills. ${ }^{39}$ Besides its application in soil remediation, its applicability is mainly limited to waste gas treatment. ${ }^{109,110,165,240}$

\section{GEL ENTRAPMENT FOR BIOMASS IMMOBILIZATION}

Buchtmann et al. ${ }^{26}$ investigated an interesting concept to enhance the stability of bioreactors for the treatment of the toxic compound quinoline, which is a basic structural element of a large number of xenobiotics and is used as raw material for pesticides and pharmaceuticals production. They studied the use of biomass entrapped in polyvinyl alcohol gel beads in comparison to attached biofilm carrier and found that after a quinoline loading shock, the gel entrapment carrier biomass recovered faster and at a higher removal rate than the attached growth carriers tested. The results under stationary conditions did not differ significantly. The gel beads are thought to increase the diffusion resistance for the toxic compound and consequently decrease the actual concentration of toxic compound seen by the microorganisms. ${ }^{26}$ Under stationary conditions, the microorganisms grew, and as such some gel beads disrupted, ultimately resulting in biofilm formation on the outside comparable to that on attached growth carriers. ${ }^{26}$ Although this reactor was operated for 66 days, long-term stability of the gel beads in such systems needs to be evaluated. Bettmann and Rehm ${ }^{15}$ used the same principle for the degradation of phenol and found that the in polyacrylamide-hydrazide (PAAH) gel, entrapped Pseudomonas sp. could degrade phenol concentrations up to $3 \mathrm{~g} \mathrm{~L}^{-1}$, whereas in suspended growth, the maximum concentration that could be degraded was $1.5 \mathrm{~g} \mathrm{~L}^{-1}$. Furthermore, complete degradation was 
achieved considerably faster with the gel beads ( $25 \mathrm{~h}$ vs. $48 \mathrm{~h}^{14}$ ). In continuous operation of a fluidized bed reactor applying PAAH entrapped PS. putida, Bettmann and Rehm ${ }^{16}$ obtained stable phenol degradation at a rate of $7.2 \mathrm{~g} \mathrm{~L}^{-1} \mathrm{~d}^{-1}$ under sterile conditions, whereas under non-sterile conditions using municipal wastewater, a maximum degradation rate of $3.12 \mathrm{~g} \mathrm{~L}^{-1} \mathrm{~d}^{-1}$ was obtained. In batch experiments, Ehrhardt and Rehm ${ }^{54}$ found that phenol spikes of up to $15 \mathrm{~g} \mathrm{~L}^{-1}$ in a system, using activated carbon immobilized Pseudomonas and Candida sp., did not result in complete inhibition of the system due to a great adsorption capacity of the used activated carbon, as well as the biological degradation activity. In addition, Mörsen and Rehm ${ }^{155}$ found degradation activity in GAC immobilized cultures up to $17 \mathrm{~g} \mathrm{~L}^{-1}$. Although the principle of using gel entrapped microorganisms seems interesting to reduce toxicity, reduction of toxicity also occurs due to adsorption of a toxic compound to activated carbon, which for practical applications seems simpler.

Ferschl et al. ${ }^{69}$ investigated the use of calcium-alginate entrapped Pseudomonas acidovorans for the continuous degradation of 3-chloroaniline. They found that the degradation rate of 3-chloroaniline at $1.06 \mathrm{~g} \mathrm{~L}^{-1} \mathrm{~d}^{-1}$ was about four times that of growth in suspended cultures. Westmeier and Rehm $^{223}$ demonstrated the biodegradation of 4-chlorophenol by calciumalginate entrapped cells of an Alcaligenes sp. to be more tolerant to higher concentrations and achieved degradation rates of $0.25 \mathrm{~g} \mathrm{~L}^{-1} \mathrm{~d}^{-1}$ in unbuffered cultures. The stability of these gel beads was rather low as in phosphate buffered cultures, despite the fact that a higher degradation rate of $0.5 \mathrm{~g} \mathrm{~L}^{-1} \mathrm{~d}^{-1}$ was observed, the gel beads dissolved in a matter of days. Although the principle of gel-entrapped biomass has been demonstrated, the experiments previously mentioned were either batch or short-term continuous experiments (several days up to a maximum of nine weeks). Pai et al. ${ }^{166}$ also reports that although alginate beads could immobilize defined mixed microbial cultures that mediate various reactions, their reported short lifetime of 80 days limits practical applications. Moreover, in their experiments, they observed that although the phenol removal rate by gel-entrapped Rbodococcus sp. was higher at influent concentrations of $1 \mathrm{~g} \mathrm{~L}^{-1}$ compared with the same microorganisms immobilized on GAC, the latter were more stable in providing consistent cellular activity during dissolved oxygen and $\mathrm{pH}$ changes. ${ }^{166}$

The application of gel entrapment is highly dependent on the long-term stability of the gel material. It should be inert, insoluble in the medium, non-biodegradable, and mechanically stable under reactor operation. ${ }^{219} \mathrm{Vo}-$ gelsang et al. ${ }^{219}$ investigated the properties of polyvinyl alcohol with stilbazolium groups for immobilization and reported that this material is very soft and super elastic and, as a result, showed no significant fatigue and abrasion. For immobilization of nitrifying bacteria in the treatment of domestic wastewater, they maintained their physical integrity for more than 
two years. ${ }^{217}$ Furthermore, storage for 2-3 months by drying or freezing was possible and the activity could be fully recovered in 4 to 9 days, although immediate activity was higher for the gel beads that had been frozen $(10 \%$ vs. $60 \%$ immediate activity). ${ }^{218}$

\section{DYNAMIC CONDITIONS IN SEQUENCING BATCH REACTORS}

For wastewater treatment, the treatment in continuously stirred tank reactors has been generally considered as the best solution as they operate at low substrate concentrations, which indicates that the toxic effect of xenobiotic compounds on the biomass activity is reduced. ${ }^{198}$ However, capabilities of biomass for the degradation of biorefractory compounds are determined by the induction of the synthesis of enzymes that can lead to specific metabolic pathways, which are favored by dynamic conditions that are typical of periodic systems, such as occurring in a SBR. ${ }^{198}$ These reactors are characterized by cyclic operation constituting of a period of filling, a reaction period, a settling period, and finally withdrawal of effluent. Tomei et al. 197,198 demonstrated the use of an SBR reactor for the successful biodegradation of 4-nitrophenol. SBR operation for the treatment of wastewater containing chlorophenols revealed a more homogeneous distribution of the biofilm covering the $\mathrm{O}_{2}$ permeable membranes used, resulting in similar removal rates in different sections of the reactor and better handling of shock loads. ${ }^{230}$ This contrasts with the observed biofilm stratification and uneven biomass distribution in continuous flow mode normally used in wastewater treatment facilities. ${ }^{233}$ In case of a more even biomass distribution, the microorganisms throughout the biofilm achieve higher growth rates, which cause physiological adaptations that improve the response to shock loads. ${ }^{233}$

In a SBR, the biomass grows under extreme dynamic substrate conditions, but dynamic substrate conditions occur in most wastewater treatment systems, even though the overall process presents steady-state conditions. ${ }^{139}$ A physiological treat of bacteria to deal with varying substrate concentrations is the production of storage polymers, such as poly- $\beta$-hydroxyalkanoates, lipids, and glycogen, as their synthesis is more simple and faster than that of whole cells and requires less physiological adaptation to deal with increased substrate concentrations. ${ }^{111,138,139}$ This indicates that microorganisms subjected to dynamic feeding regimes are likely to show an enhanced storage capacity, which will be advantageous under shock load conditions. Majone et al. ${ }^{139}$ also report that floc-forming bacteria seem to have a higher ability for storage than filamentous microorganisms, which results in a competitive advantage for floc-formers. This is in agreement with observations that activated sludge systems with a high sludge volume index (SVI) — that is, sludge that does not settle well-had low storage capacity. ${ }^{111}$ The inability of storing polymers will lead to out-competition in famine periods ${ }^{111}$ and may be used to select for well settling sludge in a SBR. 
Recent developments in cultivation of aerobic granular sludge in SBR combine the advantages of dynamic reactor operation and high concentrations of immobilized biomass. ${ }^{17}$ With the recent advances in the understanding and control of the stability of aerobic granular sludge, ${ }^{132,133}$ this process holds a promise for application in industrial wastewater treatment containing toxic or inhibitory compounds. However, the development of aerobic granules has been mostly studied with simple substrates such as acetate and glucose. Only a few studies have demonstrated aerobic granulation using "real" wastewaters such as molasses, ${ }^{154}$ malting wastewater, ${ }^{182}$ and pharmaceutical wastewater. ${ }^{87}$ In the latter study, it was shown that although pharmaceutical wastewater could be treated in an SBR with granular biomass, variations in the wastewater caused a destabilization and loss of granules as well as reduced COD removal efficiency. ${ }^{87}$ This was ascribed to the limited stability of the granular sludge, as the pharmaceutical wastewater was treated in an activated sludge plant without major malfunctions. ${ }^{87}$

Whereas granule stability remains an important research issue, researchers increasingly focus their attention on studying degradation of inhibitory industrial wastewater pollutants. Aerobic granules have been cultivated for the degradation of phenol, using either activated sludge ${ }^{2,92}$ or acetate pre-grown granules, resulting in a fast start-up of the phenoldegrading SBR. ${ }^{192}$ Tay et al. ${ }^{193}$ showed further that activated sludge used in a SBR with a four-hour cycle at a phenol load of $1.8 \mathrm{~g} \mathrm{~L}^{-1} \mathrm{~d}^{-1}$ washed out within four days, whereas a SBR inoculated with acetate pre-grown aerobic granules operated under the same conditions nearly completely removed all phenol from the effluent from day 3 onward. Jiang et al. ${ }^{93}$ investigated the structure, activity, and metabolism of aerobic granules as a microbial response to high phenol loads and found compact granules at loads up to $2.0 \mathrm{~g} \mathrm{~L}^{-1} \mathrm{~d}^{-1}$, whereas weak granules were observed at $2.5 \mathrm{~g} \mathrm{~L}^{-1} \mathrm{~d}^{-1}$. At the highest load, they also found an enhanced EPS production and a higher amount of protein, which could indicate that the membrane structure of the cells was modified as a response to high phenol concentrations, as higher amounts of proteins have been indicated to increase the rigidity of the lipid fatty acyl chains. ${ }^{93}$ Furthermore, they observed that the metabolic route for phenol degradation changed from mainly meta-cleavage to exclusively meta-cleavage, which yields more energy and might have been required for maintaining the cell membrane integrity and excess EPS production. ${ }^{93}$ More recently, the degradation of tert-butyl alcohol ${ }^{245}$ and $p$-nitrophenol ${ }^{241}$ with aerobic granular sludge in SBR has also been demonstrated.

\section{STABILITY OF ANAEROBIC SYSTEMS}

Despite the lower energy consumption and low sludge production, anaerobic wastewater treatment processes have been indicated to be unstable 
and unable to deal with high load variations. Leitão et al. ${ }^{123}$ recently reviewed the effects of operational and environmental variations on anaerobic wastewater treatment systems and concluded that stability or robustness of anaerobic reactors is still rather confusing. In regard to robustness of the system to reach steady-state performance, they conclude that anaerobic systems are as stable as other biological processes, but when stability was defined as the capacity to deal with more severe environmental and operational variations, serious problems of reliability may manifest. Furthermore, recovery after a serious reactor upset shock is likely to proceed slowly due to the generally low growth rates of anaerobic microorganisms compared to aerobic microorganisms, ${ }^{195}$ which become even more pronounced at low temperatures. $^{123}$

Anaerobic treatment of wastewaters depends more than its aerobic counterpart on intimate syntrophic relations between different trophic groups, in sequentially arrangement, for the complete biodegradation of the pollutants. ${ }^{195}$ As different trophic groups react differently on environmental factors (e.g., resulting in accumulation of VFA or changes in $\mathrm{pH}$ ), small imbalances thus created may ultimately lead to complete malfunctioning of anaerobic treatment processes. ${ }^{65}$ Thiele and Zeikus ${ }^{195}$ developed the anionexchange substrate shuttle process as an approach to two-stage biomethanation of toxic wastes, in which the ultimate and most sensitive steps in anaerobic mineralization are protected from toxic compounds or inhibiting concentrations of substrate. They physically separated acidification from methanogenesis, which were connected via an anion exchange unit. Acidifiers are known to grow faster and are more resistant to metabolic inhibition by protons, VFA, and $\mathrm{H}_{2}$ upon shock loads. ${ }^{195}$ The anion exchange unit adsorbs the VFA in the acidification reactor, and due to exchange for bicarbonate in the methanogenic reactor, the VFA would be released. ${ }^{195}$ Because the production of bicarbonate controls the inflow of VFA, no substrate overload can occur. Other advantages were the extremely high conversion rates of up to $430 \mathrm{~kg}$ COD m $\mathrm{m}^{-3} \mathrm{~d}^{-1}$ that could be obtained-whereas in UASB reactors maximal conversion rates have been reported at about $100 \mathrm{~kg} \mathrm{COD} \mathrm{m}^{-3}$ $\mathrm{d}^{-1}$ - and the high methane content of the biogas from the methanogenic reactor. ${ }^{195}$ Unfortunately, this process only works for fatty acids, whereas alcohols or $\mathrm{H}_{2}$, which are important intermediates in anaerobic mineralization, could not be handled by this process. This is probably the reason why this process did not receive much attention afterward.

A compartmentalized approach as occurs in anaerobic baffled reactors has shown a high stability toward shock loads of easily degradable and acidifying wastewaters. ${ }^{158,159}$ They found the ABR extremely stable to step changes in feed COD, which was ascribed to the reactor structure (see Figure 1B) that prevents much of the biomass being exposed to low $\mathrm{pH}$ during organic shock loads. The ABR was described as having three functional different reactor parts (viz., acidification, methanation, and buffer parts). ${ }^{158}$ 
Baloch and Akunna ${ }^{10}$ also demonstrated the stability upon hydraulic shock loads in a granular ABR. Previously, Grobicki and Stuckey ${ }^{77}$ reported that during shock loads, high formate and only little propionate accumulation in an ABR were beneficial for the fast recovery, as methanogenesis from formate is faster than from acetate or $\mathrm{H}_{2}$.

Anaerobic immobilized biofilm reactors have been shown to degrade toxic compounds, including phenol, ${ }^{18}$ chlorinated phenols, ${ }^{112}$ toluene, ${ }^{34}$ and BTEX. $^{44,45}$ Furthermore, nearly full dechlorination of PCP was observed both in a biofilm reactor inoculated with anaerobic digested sewage sludge and in an UASB inoculated with granular anaerobic sludge. ${ }^{81}$ They maintained dechlorination for more than 18 months in both reactors, although the performance of the UASB was better. Other investigators have also reported the successful degradation of PCP- and/or phenol-containing wastewaters in an UASB reactor. ${ }^{52,63,236}$ This, together with the reported successful anaerobic degradation of toluene, acetone, and 2,4,6-trichlorophenol, ${ }^{37,60,61}$ indicates that anaerobic processes can deal with complex and toxic wastewaters as generated in industrial processes. Some compounds degrade faster or may even require anaerobic conditions during the initial biodegradation steps (e.g., azo dyes cleavage ${ }^{50}$ or heavy metal removal using the sulfide produced from sulfate/sulfite under anaerobic conditions). ${ }^{124}$ Nevertheless, other compounds have been found mostly inert under anaerobic conditions, such as linear alkylbenzene sulfonates. ${ }^{91,172}$

\section{MICROBIAL DIVERSITY AND POPULATION DYNAMICS}

Overall stable performance of biological wastewater treatment is usually achieved with microbial communities, which are stable under normal operating conditions but able to adapt in response to perturbations to maintain high effluent quality. ${ }^{116}$ Smith et al. ${ }^{185}$ analyzed the composition of the bacterial community in a pulp mill wastewater treatment system, which was stable during normal operation as well as during shutdown and startup. This stability coincided with functional stability, including consistent and a near complete biological oxygen demand removal. However, Miura et al. ${ }^{147}$ showed that after 100 days of operation of different MBRs, small perpetual fluctuations in the bacteria community occurred, despite the fact that the effluent quality of the permeate was stable. This indicates that although the microbial community was dynamic, the overall process reached functional stability. Dynamic microbial communities can be the result of temporal fluctuation of environmental parameters, predation, and biomass decay. ${ }^{147}$

LaPara et al. ${ }^{116}$ investigated the stability of microbial communities treating pharmaceutical wastewater. Although the effluent quality was 
consistently high and stable, communities were dynamic and showed moderate community shifts. They report that short-term variability in influent wastewater composition affected a greater community shift than long-term operation treating a wastewater of relative consistent composition and further suggested that an increased diversity results in higher stability of the overall process. ${ }^{116}$ Fernandez et al. ${ }^{65}$ reported that during stable performance, an extremely dynamic community can maintain a stable ecosystem function. For anaerobic systems, it was found that a higher species diversity or community stability was not directly related to functional stability under perturbated loading of glucose. ${ }^{66}$ Rather, stability is linked to community flexibility, which is reflected in the ability to shift electron and carbon flows via alternative routes in an efficient way. ${ }^{66}$ They showed that the more functional stable reactor showed the largest changes in microbial composition. Kaewpipat and $\mathrm{Grady}^{96}$ demonstrated that two reactors operating under similar conditions and showing similar performance diverged after 60 days in respect to the microbial populations present.

Fairly stable communities during degradation of aromatic compounds such as styrene, benzenes toluene, and fluorobenzene have been reported. ${ }^{32,185,199}$ Baptista et al. ${ }^{11}$ investigated the stability and performance of communities containing Xantbobacter autotrophicus GJ10 during 1,2dichloroethane biodegradation in a non-sterile CSTR. This strain was the dominant species (85\% of total community) in the reactor when degrading solely 1,2-dichloroethane, but rapidly decreased to $8 \%$ of the total microbial community after the addition of glucose in the feed. Despite the drastic reduction of the relative contribution to the total microbial community, the degradation of 1,2-dichloroethane remained similar, revealing functional stability of the process. Emanuelsson et al. ${ }^{57}$ demonstrated that $X$. autotrophicus GJ10 remained the dominant species in a reactor degrading 1,2-dichloroethane, even after introduction of foreign microorganisms with a pulse of industrial wastewater treating sludge. In another reactor, inoculated with Burkbolderia sp. JS150 for the treatment of monochlorobenzene, the specific strain disappeared within a week upon the addition of industrial sludge, although this did not affect the functional stability. ${ }^{57}$ Stable communities have been reported in previous studies on the degradation of xenobiotic compounds, such as 2-fluorobenzoate or fluorobenzene in GAC and expanded clay biofilm reactors. ${ }^{32,58}$ The stability of these microbial communities was most likely due to the fact that the substrates fed to the systems were xenobiotic compounds, and the specific capacity of the inoculated strains for the degradation of such xenobiotics prevent them from being outcompeted by other microorganisms. This indicates that the type of substrate and possibly typical characteristics of the microorganisms involved in their degradation will ultimately determine the survival of introduced microorganisms under non-sterile conditions. 
The successful bioaugmentation with foreign microorganisms in wastewater treatment plants most likely depends on the capacity of these introduced species to perform key roles in the degradation of specific compounds previously refractory within the treatment or protect other microorganisms by reducing toxicity. The latter was shown in activated sludge systems for protection of toxic phenol shocks ${ }^{56}$ and 3-chloroaniline shocks. ${ }^{20}$ Phenol shock loads drastically decreased microbial diversity, but after the introduction of a GEM capable of phenol degradation, a high diversity of microorganisms was observed throughout the shock load. ${ }^{56}$ In the case of 3 -chloroaniline shocks, the COD removal efficiency dropped by 36\%, and nitrification inhibition resulted in the accumulation of ammonium in nonbioaugmented reactors, whereas in bioaugmented reactors no COD removal decrease was observed and nitrification was only shortly inhibited but recovered quickly. ${ }^{20}$

Community analysis of a biotrickling filter under sequential alternating pollutant scenario revealed structural changes upon each change of substrate. ${ }^{29,59}$ Under these sequential alternating pollutant scenarios, bacteria may experience periods of substrate starvation. During these starvation periods, bacteria may use internally stored polymers for growth and maintenance processes, which is known as endogenous respiration. ${ }^{210}$ Van Loosdrecht and Henze ${ }^{210}$ further report that internal decay does not seem to reduce the number of microorganisms significantly, but rather reduces the weight and activity of the biomass. External decay, via predation or cell lysis, however, can become important in complex systems like activated sludge plants. ${ }^{210}$ Predation and cell lysis probably affect the amount of bacteria most in biofilm systems, as it has been suggested that bacteria do not die by themselves. ${ }^{210}$ Kaprelyants et al. ${ }^{98}$ found that Micrococcus luteus showed a culturability of less than $0.001 \%$ after starvation periods of 2 to 7 months; however, when the liquid media was taken from the stationary phase of batch cultures, the viability was found to be 1000- to 100,000-fold greater. This suggests that viable cells can produce a factor, which stimulates the resuscitation of dormant cells. Therefore, it was concluded that at least a significant fraction of apparently non-viable cells were dormant and not dead. ${ }^{98}$ Cell dormancy in starvation periods can be compared to the formation of spores to survive unfavorable conditions. Nevertheless, starvation periods affect metabolic activity and may lead to more or less washout of microorganisms, depending on the type of treatment system employed, thus resulting in decreased removal efficiencies when feeding is resumed.

\section{CONCLUSIONS}

Biological treatment of industrial wastewater can prove difficult due to the characteristics of the wastewater that are often highly variable in time. 
Changing substrate loads may lead to decreased removal efficiencies or even upset microbial interactions, causing complete failure of the treatment. Extreme environmental conditions occurring in these wastewaters may seriously hamper its treatability. Such a reduced treatability becomes more pronounced if these environmental conditions are not constant but rather variable. Industrial processes in especially the fine chemical and pharmaceutical industry are often characterized by batch production, giving rise to rapid swings in pollutant, which may result in starvation experienced by part of the microbial community. Furthermore, the presence of toxic or inhibitory pollutants may be detrimental to the treatment process. This implies that a good characterization and toxicity screening of the influent to biological industrial wastewater treatment facilities needs careful monitoring in order to prevent malfunctioning.

A prerequisite for handling highly variable wastewaters is a high biomass density in the treatment plant, suggesting that the potential of conventional activated sludge plants is limited. Reactors with a high degree of biomass retention, such as immobilized biofilm reactors or MBRs, are advantageous in dealing with variable influents. The high amount of biomass in these systems results in compact reactors with the capacity to achieve high removal efficiency even at variable loads. In immobilized biofilm reactors, the layered growth within an EPS matrix protects microorganisms from high concentrations of toxic pollutants in the bulk liquid. Furthermore, EPS may assist in the degradation of slowly degradable pollutants by their entrapment into the EPS matrix, which facilitates long contact periods of pollutants and microorganisms and is highly beneficial for their degradation. Biofilm formation on activated carbon will for many pollutants result in similar, although strongly enhanced, effects of lower bulk pollutant concentrations and longer contact periods.

Most continuous flow reactors are characterized by more or less constant conditions (i.e., when the influent wastewater is relatively stable in terms of loads, substrates, $\mathrm{pH}$, temperature, salinity, and toxicant concentration). However, for fluctuating influent characteristics, these reactors may react rather static to the imposed changes. Dynamic operated reactors, such as SBRs, experience rather large variations under normal operation, and are therefore expected to handle fluctuations in the influent more easily. Biofilm reactors operated under such dynamic operating conditions have shown more evenly distributed growth, which enables them to handle greater variations in organic loads. This also indicates that instead of stable microbial communities, rather diverse and flexible communities are desired, capable of handling influent variations.

The ultimate aim for biological treatment of industrial wastewater is to achieve an efficient and stable pollutant removal for which a choice can be made from many processes developed. This indicates that depending on the type of wastewater and the variations occurring, an efficient and functionally 
stable biological treatment of most industrial wastewaters can be designed taking into account the specifics of the treatment system and the wastewater.

\section{ACKNOWLEDGMENTS}

This research was supported by the EU Research Training Network Biotreatment of sequentially alternating pollutants in wastewaters, contract number HPRTN-CT-2002-00213. J. Sipma and M.B. Osuna gratefully acknowledge their Marie Curie Post-Doctoral grants and M.A.E. Emanuelsson gratefully acknowledges her Marie Curie Pre-Doctoral grant.

\section{REFERENCES}

[1] Abu-Salah, K., Shelef, G., Levanon, D., Armon, R., and Dosoretz, C.G. (1996). Microbial degradation of aromatic and polyaromatic toxic compounds adsorbed on powdered activated carbon. J. Biotechnol., 51(3), 265-272.

[2] Adav, S.S., Chen, M.-Y., Lee, D.-J., and Ren, N.-Q. (2007). Degradation of phenol by aerobic granules and isolated yeast Candida tropicalis. Biotechnol. Bioeng., 96(5), 844-852.

[3] Al-Sharekh, H.A., and Hamoda, M.F. (2001). Removal of organics from wastewater using a novel biological hybrid system. Water Sci. Technol., 43(1), 321-326.

[4] Alva, V.A., and Peyton, B.M. (2003). Phenol and catechol biodegradation by the haloalkaliphile Halomonas campisalis: Influence of $\mathrm{pH}$ and salinity. Environ. Sci. Technol., 37(19), 4397-4402.

[5] Amorim, A.K.B., Zaiat, M., and Foresti, E. (2005). Performance and stability of an anaerobic fixed bed reactor subjected to progressive increasing concentrations of influent organic matter and organic shock loads. J. Environ. Manag., 76(4), 319-325.

[6] Aquino, S.F., and Stuckey, D.C. (2004). Soluble microbial products formation in anaerobic chemostats in the presence of toxic compounds. Water Res., 38(2), $255-266$.

[7] Aquino, S.F., and Stuckey, D.C. (2004). The effect of organic and hydraulic shock loads on the production of soluble microbial products in anaerobic digesters. Water Environ. Res., 76(7), 2628-2636.

[8] Austermann-Haun, U., Lange, R., Seyfried, C.-F., and Rosenwinkel, K.-H. (1998). Upgrading an anaerobic/aerobic wastewater treatment plant. Water Sci. Technol., 37(9), 243-250.

[9] Bae, J.H., and McCarty, P.L. (1993). Variation of carbon-monoxide production during methane fermentation of glucose. Water Environ. Res., 65(7), 890-898.

[10] Baloch, M.I., and Akunna, J.C. (2003). Effect of rapid hydraulic shock loads on the performance of granular bed baffled reactor. Environ. Technol., 24(3), 361-368.

[11] Baptista, I.I.R., Peeva, L.G., Zhou, N.-Y., Leak, D.J., Mantalaris, A., and Livingston, A.G. (2006). Stability and performance of Xanthobacter 
autotrophicus GJ10 during 1,2-dichloroethane biodegradation. Appl. Environ. Microbiol., 72(6), 4411-4418.

[12] Barker, D.J., and Stuckey, D.C. (1999). A review of soluble microbial products (SMP) in wastewater treatment systems. Water Res., 33(14), 3063-3082.

[13] Beg, S.A., Hassan, M.M., and Chaudry, M.A.S. (1995). Response of a packed bed biological reactor to perturbation of feed concentration and temperature. Intern. J. Environ. Studies, 49(1), 31-52.

[14] Benitez, F.J., Acero, J.L., Garcia, J., and Leal, A.I. (2003). Purification of cork processing wastewaters by ozone, by activated sludge, and by their two sequential applications. Water Res., 37(17), 4081-4090.

[15] Bettmann, H., and Rehm, H.J. (1984). Degradation of phenol by polymer entrapped microorganisms. Appl. Microbiol. Biotechnol., 20(5), 285-290.

[16] Bettmann, H., and Rehm, H.J. (1985). Continuous degradation of phenol(s) by Pseudomonas putida P8 entrapped in polyacrylamidehydrazide. Appl. Microbiol. Biotechnol., 22(6), 389-393.

[17] Beun, J.J., van Loosdrecht, M.C.M., and Heijnen, J.J. (2002). Aerobic granulation in a sequencing batch airlift reactor. Water Res., 36(3), 702-712.

[18] Bolaños, R.M.L., Varesche, M.B.A., Zaiat, M., and Foresti, E. (2001). Phenol degradation in horizontal-flow anaerobic immobilized biomass (HAIB) reactor under mesophilic conditions. Water Sci. Technol., 44(4), 167-174.

[19] Boon, N., Goris, J., De Vos, P., Verstraete, W., and Top, E.M. (2000). Bioaugmentation of activated sludge by an indigenous 3-chloroaniline-degrading Comamonas testosteroni strain, I2gfp. Appl. Environ. Microbiol., 66(7), 2906-2913.

[20] Boon, N., Top, E.M., Verstraete, W., and Siciliano, S.D. (2003). Bioaugmentation as a tool to protect the structure and function of an activated-sludge microbial community against a 3-chloroaniline shock load. Appl. Environ. Microbiol., 69(3), 1511-1520.

[21] Boopathy, R., Larsen, V.F., and Senior, E. (1988). Performance of anaerobic baffled reactor $(\mathrm{ABR})$ in treating distillery waste water from a scotch whisky factory. Biomass, 16(2), 133-143.

[22] Boyd, E.M., Killham, K., Wright, J., Rumford, S., Hetheridge, M., Cumming, R., and Meharg, A.A. (1997). Toxicity assessment of xenobiotic contaminated groundwater using lux modified Pseudomonas fluorescens. Chemosphere, 35(9), 1967-1985.

[23] Brouwer, H. (1991). Testing for chemical toxicity using bacteria: An undergraduate laboratory experiment. J. Chemical Educat., 68(8), 695-697.

[24] Brown, J.S., Rattray, E.A.S., Paton, G.I., Reid, G., Caffoor, I., and Killham, K. (1996). Comparative assessment of the toxicity of a papermill effluent by respirometry and a luminescence-based bacterial assay. Chemosphere, 32(8), 1553-1561.

[25] Brown, M.L., Aldrich, H.C., and Gauthier, J.J. (1995). Relationship between glycocalyx and povidone-iodine resistance in Pseudomonas aeruginosa (ATCC 27853) biofilms. Appl. Environ. Microbiol., 61(1), 187-193.

[26] Buchtmann, C., Kies, U., Deckwer, W.-D., and Hecht, V. (1997). Performance of three phase fluidized bed reactor for quinoline degradation on various supports at steady state and dynamic conditions. Biotechnol. Bioeng., 56(3), 295-303. 
[27] Buitron, G., Soto, G., Vite, G., and Moreno, J. (2001). Strategies to enhance the biodegradation of toxic compounds using discontinuous processes. Water Sci. Technol., 43(3), 283-290.

[28] Bury, S.J., Groot, C.K., Huth, C., and Hardt, N. (2002). Dynamic simulation of chemical industry wastewater treatment plants. Water Sci. Technol., 45(4-5), 355-363.

[29] Cai, Z., Kim, D., Sorial, G.A., Saikaly, P., Zein, M.M., and Oerther, D.B. (2006). Performance and microbial diversity of a trickle-bed air biofilter under interchanging contaminants. Eng. Life Sci., 6(1), 37-42.

[30] Caldeira, M., Heald, S.C., Carvalho, M.F., Vasconcelos, I., Bull, A.T., and Castro, P.M.L. (1999). 4-Chlorophenol degradation by a bacterial consortium: Development of a granular activated carbon biofilm reactor. Appl. Microbiol. Biotechnol., 52(5), 722-729.

[31] Carvalho, M.F., Vasconcelos, I., Bull, A.T., and Castro, P.M.L. (2001). A GAC biofilm reactor for the continuous degradation of 4-chlorophenol: Treatment efficiency and microbial analysis. Appl. Microbiol. Biotechnol., 57(3), 419426.

[32] Carvalho, M.F., Ferreira Jorge, R., Pacheco, C.C., De Marco, P., Henriques, I.S., Correia, A., and Castro, P.M.L. (2006). Long-term performance and microbial dynamics of an up-flow fixed bed reactor established for the biodegradation of fluorobenzene. Appl. Microbiol. Biotechnol., 71(4), 555-562.

[33] Carvalho, M.F., Duque, A.F., Gonçalves, I.C., and Castro, P.M.L. (2007). Adsorption of fluorobenzene onto granular activated carbon: Isotherm and bioavailability studies. Biores. Technol., 98(18), 3424-3430.

[34] Cattony, E.B.M., Chinalia, F.A., Ribeiro, R., Zaiat, M., Foresti, E., and Varesche, M.B.A. (2005). Ethanol and toluene removal in a horizontal-flow anaerobic immobilized biomass reactor in the presence of sulfate. Biotechnol. Bioeng., 91(2), 244-253.

[35] Chong, N.-M., Pai, S.-L., and Chen, C.-H. (1997). Bioaugmentation of an activated sludge receiving pH shock loadings. Biores. Technol., 59(2-3), 235-240.

[36] Chua, H., and Chen, Y.F. (1995). A novel adsorption-anaerobiosis column for the removal of persistent organics from contaminated water. Marine Poll. Bull., 31(4-12), 313-316.

[37] Collins, G., Foy, C., McHugh, S., and O'Flaherty, V. (2005). Anaerobic treatment of 2,4,6-trichlorophenol in an expanded granular sludge bed-anaerobic filter (EGSB-AF) bioreactor at $15^{\circ} \mathrm{C}$. FEMS Microbiol. Ecol., 53(1), 167-178.

[38] Collins, L.D., and Daugulis, A.J. (1997). Biodegradation of phenol at high initial concentrations in two-phase partitioning batch and fed-batch bioreactors. Biotechnol. Bioeng., 55(1), 155-162.

[39] Collins, L.D., and Daugulis, A.J. (1999). Simultaneous biodegradation of benzene, toluene, and $p$-xylene in a two-phase partitioning bioreactor: Concept demonstration and practical application. Biotechnol. Prog., 15(1),74-80.

[40] Comte, S., Guibaud, G., and Baudu, M. (2006). Biosorption properties of extracellular polymeric substances (EPS) resulting from activated sludge according to their type: Soluble or bound. Proc. Biochem., 41(4), 815-823.

[41] Dalzell, D.J.B., Alte, S., Aspichueta, E., de la Sota, A., Etxebarria, J., Gutierrez, M., Hoffmann, C.C., Sales, D., Obst, U., and Christofi, N. (2002). A 
comparison of five rapid direct toxicity assessment methods to determine toxicity of pollutants to activated sludge. Chemosphere, 47(5), 535-545.

[42] Davies, D.G., Parsek, M.R., Pearson, J.P., Iglewski, B.H., Costerton, J.W., and Greenberg, E.P. (1998). The involvement of cell-to-cell signals in the development of a bacterial biofilm. Science, 280(5361), 295-298.

[43] Davies, D.G. (1999). Regulation of matrix polymer in biofilm formation and dispersion. In: Wingender, J., Neu, T.R., and Flemming, H.-C. (eds.). Microbial extracellular polymeric substances: Characterization, structure and function. Springer, Berlin, pp. 93-117.

[44] De Nardi, I.R., Varesche, M.B.A., Zaiat, M., and Foresti, E. (2002). Anaerobic degradation of BTEX in a packed-bed reactor. Water Sci. Technol., 45(10), 175-180.

[45] De Nardi, I.R., Ribeiro, R., Zaiat, M., and Foresti, E. (2005). Anaerobic packed-bed reactor for bioremediation of gasoline-contaminated aquifers. Proc. Biochem., 40(2), 587-592.

[46] Delee, W., O'Neill, C., Hawkes, F.R., and Pinheiro, H.M. (1998). Anaerobic treatment of textile effluents: A review. J. Chem. Technol. Biotechnol., 73(4), 323-335.

[47] Deshusses, M.A., Hamer, G., and Dunn, I.J. (1995). Behavior of biofilters for waste air biotreatment. 1. Dynamic model development. Environ. Sci. Technol., 29(4), 1048-1058.

[48] Deshusses, M.A., Hamer, G., and Dunn, I.J. (1996). Transient-state behavior of a biofilter removing mixtures of vapors of MEK and MIBK from air. Biotechnol. Bioeng., 49(5), 587-598.

[49] Di Iaconi, C., Bonemazzi, F., Lopez, A., and Ramadori, R. (2004). Integration of chemical and biological oxidation in a SBBR for tannery wastewater treatment. Water Sci. Technol., 50(10), 107-114.

[50] Dos Santos, A.B., Cervantes, F.J., and Van Lier, J.B. (2007). Review paper on current technologies for decolourisation of textile wastewaters: Perspectives for anaerobic biotechnology. Biores. Technol., 98(12), 23692385.

[51] Droste, R.L. (1997). Theory and practice of water and wastewater treatment. John Wiley \& Sons Inc., Hoboken, NJ.

[52] Duff, S.J.B., Kennedy, K.J., and Brady, A.J. (1995). Treatment of dilute phenol/PCP wastewaters using the upflow anaerobic sludge blanket (UASB) reactor. Water Res., 29(2), 645-651.

[53] Eckenfelder, W.W. (1989). Industrial water pollution control. International ed. McGraw-Hill, Inc., New York.

[54] Ehrhardt, H.M., and Rehm, H.J. (1985). Phenol degradation by microorganisms adsorbed on activated carbon. Appl. Microbiol. Biotechnol., 21(1-2), 32-36.

[55] Ehrhardt, H.M., and Rehm, H.-J. (1989). Semi continuous and continuous degradation of phenol by Pseudomonas putida P8 adsorbed on activated carbon. Appl. Microbiol. Biotechnol., 30(3), 312-317.

[56] Eichner, C.A., Erb, R.W., Timmis, K.N., and Wagner-Döbler, I. (1999). Thermal gradient gel electrophoresis analysis of bioprotection from pollutant shocks in the activated sludge microbial community. Appl. Environ. Microbiol., 65(1), 102-109. 
[57] Emanuelsson, E.A.C., Baptista, I.I.R., Mantalaris, A., and Livingston, A.G. (2005). Strain stability in biological systems treating recalcitrant organic compounds. Biotechnol. Bioeng., 92(7), 843-849.

[58] Emanuelsson, M.A.E., Henriques, I.S., Ferreira Jorge, R.M., and Castro, P.M.L. (2006). Biodegradation of 2-fluorobenzoate in upflow fixed bed bioreactors operated with different growth support materials. J. Chem. Technol. Biotechnol., 81(9), 1577-1585.

[59] Emanuelsson, M.A.E., Osuna, M.B., Sipma, J., and Castro, P.M.L. (2008). Treatment of halogenated organic compounds and monitoring of microbial dynamics in up-flow fixed bed reactors under sequentially alternating pollutant scenarios. Biotechnol. Bioeng., 99(4), 800-810.

[60] Enright, A.-M., McHugh, S., Collins, G., and O'Flaherty, V. (2005). Lowtemperature anaerobic biological treatment of solvent containing pharmaceutical wastewater. Water Res., 39(19), 4587-4596.

[61] Enright, A.-M., Collins, G., and O'Flaherty, V. (2007). Low-temperature anaerobic biological treatment of toluene-containing wastewater. Water Res., 41(7), 1465-1472.

[62] Esparza-Soto, M., and Westerhoff, P. (2003). Biosorption of humic and fulvic acids to live activated sludge biomass. Water Res., 37(10), 23012310.

[63] Fang, H.H.P., Chen, T., Li, Y.-Y., and Chui, H.-K. (1996). Degradation of phenol in wastewater in an upflow anaerobic sludge blanket reactor. Water Res., 30(6), 1353-1360.

[64] Feakin, S.J., Blackburn, E., and Burns, R.G. (1995). Inoculation of granular activated carbon in a fixed bed with S-triazine-degrading bacteria as a water treatment process. Water Res., 29(3), 819-825.

[65] Fernandez, A., Huang, S., Seston, S., Xing, J., Hickey, R., Criddle, C., and Tiedje, J. (1999). How stable is stable? Function versus community composition. Appl. Environ. Microbiol., 65(8), 3697-3704.

[66] Fernandez, A.S., Hashsham, S.A., Dollhopf, S.L., Raskin, L., Glagoleva, O., Dazzo, F.B., Hickey, R.F., Criddle, C.S., and Tiedje, J.M. (2000). Flexible community structure correlates with stable community function in methanogenic bioreactor communities perturbed by glucose. Appl. Environ. Microbiol., 66(9), 4058-4067.

[67] Ferreira Jorge, R.M., and Livingston, A.G. (2000). Microbial dynamics in a continuous stirred tank bioreactor exposed to an alternating sequence of organic compounds. Biotechnol. Bioeng., 69(4), 409-417.

[68] Ferreira Jorge, R.M., and Livingston, A.G. (2000). Microbial dynamics in an extractive membrane bioreactor exposed to an alternating sequence of organic compounds. Biotechnol. Bioeng., 70(3), 313-322.

[69] Ferschl, A., Loidl, M., Ditzelmiiller, G., Hinteregger, C., and Streichsbier, F. (1991). Continuous degradation of 3-chloroaniline by calcium-alginateentrapped cells of Pseudomonas acidovorans CA28: Influence of additional substrates. Appl. Microbiol. Biotechnol., 35(4), 544-550.

[70] Finlayson, J.C., Liao, B., Droppo, I.G., Leppard, G.G., and Liss, S.N. (1998). The relationship between the structure of activated sludge flocs and the sorption of hydrophobic pollutants. Water Sci. Technol., 37(4-5), 353357. 
[71] Flemming, H.-C. (1995). Sorption sites in biofilms. Water Sci. Technol., 32(8), $27-33$.

[72] Freitas dos Santos, L.M., and Livingston, A.G. (1995). Novel membrane bioreactor for detoxification of VOC wastewaters: Biodegradation of 1,2dichloroethane. Water Res., 29(1), 179-194.

[73] Fukuzaki, S., Nishio, N., and Nagai, S. (1995). High rate performance and characterization of granular methanogenic sludges in upflow anaerobic sludge blanket reactors fed with various defined substrates. J. Ferm. Bioeng., 79(4), 354-359.

[74] Galil, N.I., Schwartz-Mittelman, A., and Saroussi-Zohar, O. (1998). Biomass deflocculation and process disturbances exerted by phenol induced transient load conditions. Water Sci. Technol., 38(8-9), 105-112.

[75] Geis, S.W., Fleming, K.L., Korthals, E.T., Searle, G., Reynolds, L., and Karner, D.A. (2000). Modifications to the algal growth inhibition test for use as a regulatory assay. Environ. Toxicol. Chem., 19(1), 36-41.

[76] Goodall, J.L., and Peretti, S.W. (1998). Dynamic modeling of meta- and paranitrobenzoate metabolism by a mixed co-immobilized culture of Comamonas spp. JS46 and JS47. Biotechnol. Bioeng., 59(4), 507-516.

[77] Grobicki, A., and Stuckey, D.C. (1991). Performance of the anaerobic baffled reactor under steady-state and shock loading conditions. Biotechnol. Bioeng., 37(4), 344-355.

[78] Guibaud, G., van Hullebusch, E., and Bordas, F. (2006). Lead and cadmium biosorption by extracellular polymeric substances (EPS) extracted from activated sludges: $\mathrm{pH}$-sorption edge tests and mathematical equilibrium modeling. Chemosphere, 64(11), 1955-1962.

[79] Gutierrez, M., Etxebarria, J., and de las Fuentes, L. (2002). Evaluation of wastewater toxicity: Comparative study between Microtox and activated sludge oxygen uptake inhibition. Water Res., 36(4), 919-924.

[80] Hamer, G. (1997). Microbial consortia for multiple pollutant biodegradation. Pure Appl. Chem., 69(11), 2343-2356.

[81] Hendriksen, H.V., and Ahring, B.K. (1993). Anaerobic dechlorination of pentachlorophenol in fixed-film and upflow anaerobic sludge blanket reactors using different inocula. Biodegradation, 3(4), 399-408.

[82] Henriques, I.D.S., Holbrook, R.D., Kelly, R.T. II, and Love, N.G. (2005). The impact of floc size on respiration inhibition by soluble toxicants-a comparative investigation. Water Res., 39(12), 2559-2568.

[83] Henze, M., Gujer, W., Matsuo, T., and Van Loosdrecht, M. (2000). Activated sludge models ASM1, ASM2, ASM2d and ASM3. Scientific and technical reports. IWA Publishing, London, UK.

[84] Hickey, R.F., Vanderweilen, J., and Switzenbaum, M.S. (1987). Production of trace levels of carbon-monoxide during methanogenesis on acetate and methanol. Biotechnol. Lett., 9(1), 63-66.

[85] Hinteregger, C., and Streichsbier, F. (1997). Halomonas sp., a moderately halophilic strain, for biotreatment of saline phenolic waste-water. Biotechnol. Lett. 19(11), 1099-1102.

[86] Hwu, C.-S., Donlon, B., and Lettinga, G. (1996). Comparative toxicity of longchain fatty acid to anaerobic sludges from various origins. Water Sci. Technol., 34(5-6), 351-358. 
[87] Inizan, M., Freval, A., Cigana, J., and Meinhold, J. (2005). Aerobic granulation in a sequencing batch reactor (SBR) for industrial wastewater treatment. Water Sci. Technol., 52(10-11), 335-343.

[88] Jahren, S.J., Rintala, J.A., and Ødegaard, H. (2002). Aerobic moving bed biofilm reactor treating thermomechanical pulping whitewater under thermophilic conditions. Water Res., 36(4), 1067-1075.

[89] Jefferson, B., Laine, A.L., Judd, S.J., and Stephenson, T. (2000). Membrane bioreactors and their role in wastewater reuse. Water Sci. Technol., 41(1), 197-204.

[90] Jennings, V.L.K., Rayner-Brandes, M.H., and Bird, D.J. (2001). Assessing chemical toxicity with the bioluminescence photobacterium (Vibrio fischeri): A comparison of three commercial systems. Water Res., 35(14), 34483456.

[91] Jensen, J. (1999). Fate and effects of linear alkylbenzene sulphonates (LAS) in the terrestrial environment. Sci. Total Environ., 226(2-3), 93-111.

[92] Jiang, H.-L., Tay, J.-H., and Tay, S.T.-L. (2002). Aggregation of immobilized activated sludge cells into aerobically grown microbial granules for the aerobic biodegradation of phenol. Lett. Appl. Microbiol., 35(5), 439-445.

[93] Jiang, H.-L., Tay, J.-H., and Tay, S.T.-L. (2004). Changes in structure, activity and metabolism of aerobic granules as a microbial response to high phenol loading. Appl. Microbiol. Biotechnol., 63(5), 602-608.

[94] Jönsson, K., Grunditz, C., Dalhammar, G., and La Cour Jansen, J. (2000). Occurrence of nitrification inhibition in Swedish municipal wastewaters. Water Res., 34(9), 2455-2462.

[95] Kabdali, I., Gürel, M., and Tünay, O. (1999). Pollution prevention and waste treatment in chemical synthesis processes for pharmaceutical industry. Water Sci. Technol., 39(10-11), 265-271.

[96] Kaewpipat, K., and Grady, C.P.L., Jr. (2002). Microbial population dynamics in laboratory-scale activated sludge reactors. Water Sci. Technol., 46(1-2), $19-27$.

[97] Kapley, A., Purohit, H.J., Chhatre, S., Shanker, R., Chakrabarti, T., and Khanna, P. (1999). Osmotolerance and hydrocarbon degradation by a genetically modified microbial consortium. Biores. Technol., 67(3), 241-245.

[98] Kaprelyants, A.S., Mukamolova, G.V., and Kell, D.B. (1994). Estimation of dormant Micrococcus luteus by penicillin lysis and by resuscitation in cell-free spent culture medium at high cells dilution. FEMS Microbiol. Lett., 115(2-3), 347-352.

[99] Kazy, S.K., Sar, P., Singh, S.P., Sen, A.K., and D'Souza, S.F. (2002). Extracellular polysaccharides of a copper-sensitive and a copper-resistant Pseudomonas aeruginosa strain: Synthesis, chemical nature and copper binding. World J. Microbiol. Biotechnol., 18(6), 583-588.

[100] Keevil, C.W. (2004). The physico-chemistry of biofilm-mediated pitting corrosion of copper pipe supplying potable water. Water Sci. Technol., 49(2), 91-98.

[101] Kennedy, K.J., Lu, J., and Mohn, W.W. (1992). Biosorption of chlorophenols to anaerobic granular sludge. Water Res., 26(8), 1085-1092.

[102] Kennedy, K.J., and Pham, T.T. (1995). Effect of anaerobic sludge source and condition on biosorption of PCP. Water Res., 29(10), 2360-2366. 
[103] Khalil, E.F., Whitmore, T.N., Gamal-EI-Din, H., EI-Bassel, A., and Lloyd, D. (1988). The effects of detergents on anaerobic digestion. Appl. Microbiol. Biotechnol., 29(5), 517-522.

[104] Khodadoust, A.P., Wagner, J.A., Suidan, M.T., and Brenner, R.C. (1997). Anaerobic treatment of PCP in fluidized-bed GAC bioreactors. Water Res., 31(7), 1776-1786.

[105] Koh, S.-H., and Ellis, T.G. (2005). Protocol for early detection and evaluation of inhibitory wastewater using combined aerobic respirometric and anaerobic batch techniques. Water Environ. Res., 77(7), 3092-3100.

[106] Köhler, A., Hellweg, S., Escher, B.I., and Hungerbühler, K. (2006). Organic pollutant removal versus toxicity reduction in industrial wastewater treatment: The example of wastewater from fluorescent whitening agent production. Environ. Sci. Technol., 40(10), 3395-3401.

[107] Kong, Z., Van Rolleghem, P., Willems, P., and Verstraete, W. (1996). Simultaneous determination of inhibition kinetics of carbon oxidation and nitrification with a respirometer. Water Res., 30(4), 825-836.

[108] Koster, I.W., Rinzema, A., De Vegt, A.L., and Lettinga, G. (1986). Sulfide inhibition of the methanogenic activity of granular sludge at various $\mathrm{pH}$-levels. Water Res., 20(12), 1561-1567.

[109] Koutinas, M., Baptista, I.I., Meniconi, A., Peeva, L.G., Mantalaris, A., Castro, P.M., and Livingston, A.G. (2007). The use of an oil-absorber-bioscrubber system during biodegradation of sequentially alternating loadings of 1,2dichloroethane and fluorobenzene in a waste gas. Chem. Eng. Sci., 62(21), 5989-6001.

[110] Koutinas, M., Martin, J., Peeva, L.G., Mantalaris, A., and Livingston, A.G. (2006). An oil-absorber-bioscrubber system to stabilize biotreatment of pollutants present in waste gas. Fluctuating loads of 1,2-dichloroethane. Environ. Sci. Technol., 40(2), 595-602.

[111] Krishna, C., and Van Loosdrecht, M.C.M. (1999). Effect of temperature on storage polymers and settleability of activated sludge. Water Res., 33(10), 23742382 .

[112] Krumme, M.L., and Boyd, S.A. (1988). Reductive dechlorination of chlorinated phenols in anaerobic upflow bioreactors. Water Res., 22(2), 171-177.

[113] Kungolos, A. (2005). Evaluation of toxic properties of industrial wastewater using on-line respirometry. J. Environ. Sci. Health, Part A, 40(4), 869-880.

[114] LaPara, T.M., and Alleman, J.E. (1999). Thermophilic aerobic biological wastewater treatment. Water Res., 33(4), 895-908.

[115] LaPara, T.M., Konopka, A., Nakatsu, C.H., and Alleman, J.E. (2000). Effects of elevated temperature on bacterial community structure and function in bioreactors treating a synthetic wastewater. J. Ind. Microbiol. Biotechnol., 24(2), 140-145.

[116] LaPara, T.M., Nakatsu, C.H., Pantea, L.M., and Alleman, J.E. (2002). Stability of the bacterial communities supported by a seven-stage biological process treating pharmaceutical wastewater as revealed by PCR-DGGE. Water Res., 36(3), 638-646.

[117] Laspidou, C.S., and Rittmann, B.E. (2002). A unified theory for extracellular polymeric substances, soluble microbial products, and active and inert biomass. Water Res., 36(11), 2711-2720. 
[118] Layton, A.C., Muccini, M., Ghosh, M.M., and Sayler, G.S. (1998). Construction of a bioluminescent reporter strain to detect polychlorinated biphenyls. Appl. Environ. Microbiol., 64(12), 5023-5026.

[119] Layton, A.C., Gregory, B., Schultz, T.W., and Sayler, G.S. (1999). Validation of genetically engineered bioluminescent surfactant resistant bacteria as toxicity assessment tools. Ecotox. Environ. Safety, 43(2), 222-228.

[120] Lazarova, V., and Manem, J. (1995). Biofilm characterization and activity analysis in water and wastewater treatment. Water Res., 29(10), 2227-2245.

[121] Lee, B.-N., Lou, J.-C., and Yen, P.-C. (2002). Catalytic wet oxidation of 2,4dichlorophenol solutions: Activity of the manganese-cerium composite catalyst and biodegradability of the effluent stream. Water Environ. Res., 74(1), $28-32$.

[122] Lefebvre, O., and Moletta, R. (2006). Treatment of organic pollution in industrial saline wastewater: A literature review. Water Res., 40(20), 36713682.

[123] Leitão, R.C., van Haandel, A.C., Zeeman, G., and Lettinga, G. (2006). The effects of operational and environmental variations on anaerobic wastewater treatment systems: A review. Biores. Technol., 97(9), 1105-1118.

[124] Lens, P.N.L., Visser, A., Janssen, A.J.H., Hulshoff Pol, L.W., and Lettinga, G. (1998). Biotechnological treatment of sulfate-rich wastewaters. Crit. Env. Sci. Technol., 28(1), 41-88.

[125] Lepistö, R., and Rintala, J. (1999). Extreme thermophilic $\left(70^{\circ} \mathrm{C}\right)$, VFA-fed UASB reactor: Performance, temperature response, load potential and comparison with 35 and $55^{\circ} \mathrm{C}$ UASB reactors. Water Res., 33(14), 3162-3170.

[126] Lettinga, G., Rebac, S., and Zeeman, G. (2001). Challenge of psychrophilic anaerobic wastewater treatment. Trends Biotechnol., 19(9), 363-370.

[127] Li, X., Gao, F., Hua, Z., Du, G., and Chen, J. (2005). Treatment of synthetic wastewater by a novel MBR with granular sludge developed for controlling membrane fouling. Separ. Purif. Technol., 46(1-2), 19-25.

[128] Liao, B.Q., Allen, D.G., Droppo, I.G., Leppard, G.G., and Liss, S.N. (2001). Surface properties of sludge and their role in bioflocculation and settleability. Water Res., 35(2), 339-350.

[129] Liu, W., Howell, J.A., Arnot, T.C., and Scott, J.A. (2001). A novel extractive membrane bioreactor for treating biorefractory organic pollutants in the presence of high concentrations of inorganics: Application to a synthetic acidic effluent containing high concentrations of chlorophenol and salt. J. Membr. Sci., 181(1), 127-140.

[130] Liu, Y., Yang, S.-F., Xu, H., Woon, K.-H., Lin, Y.-M., and Tay, J.-H. (2003). Biosorption kinetics of cadmium(II) on aerobic granular sludge. Proc. Biochem., 38(7), 997-1001.

[131] Liu, Y., Xu, H., Yang, S.-F., and Tay, J.-H. (2003). A general model for biosorption of $\mathrm{Cd}^{2+}, \mathrm{Cu}^{2+}$ and $\mathrm{Zn}^{2+}$ by aerobic granules. J. Biotechnol., 102(3), 233239.

[132] Liu, Y., and Tay, J.-H. (2004). State of the art of biogranulation technology for wastewater treatment. Biotechnol. Adv., 22(7), 533-563.

[133] Liu, Y., and Liu, Q.-S. (2006). Causes and control of filamentous growth in aerobic granular sludge sequencing batch reactors. Biotechnol. Adv., 24(1), 115-127. 
[134] Livingston, A.G. (1994). Extractive membrane bioreactors: A new process technology for detoxifying chemical industry wastewaters. J. Chem. Tech. Biotechnol., 60(1), 17-24.

[135] Livingston, A.G., Arcangeli, J.-P., Boam, A.T., Zhang, S., Marangon, M., and Freitas dos Santos, L.M. (1998). Extractive membrane bioreactors for detoxification of chemical industry wastes: Process development. J. Membr. Sci., 151(1), 29-44.

[136] Livingston, A.G., Freitas dos Santos, L.M., Pavasant, P., Pistikopoulos, E.N., and Strachan, L.F. (1996). Detoxification of industrial wastewaters in an extractive membrane bioreactor. Water Sci. Technol., 33(3), 1-8.

[137] Luvsanjamba, M., Sercu, B., Kertész, S., and Van Langenhove, H. (2007). Thermophilic biotrickling filtration of a mixture of isobutyraldehyde and 2pentanone. J. Chem. Technol. Biotechnol., 82(1), 74-80.

[138] Majone, M., Massanisso, P., and Ramadori, R. (1998). Comparison of carbon storage under aerobic and anoxic conditions. Water Sci. Technol., 38(8-9), 77-84.

[139] Majone, M., Dircks, K., and Beun, J.J. (1999). Aerobic storage under dynamic conditions in activated sludge processes. The state of the art. Water Sci. Technol., 39(1), 61-73.

[140] Majumder, P.S., and Gupta, S.K. (2003). Hybrid reactor for priority pollutant nitrobenzene removal. Water Res., 37(18), 4331-4336.

[141] Mantzavinos, D., and Psillakis, E. (2004). Enhancement of biodegradability of industrial wastewaters by chemical oxidation pre-treatment. J. Chem. Technol. Biotechnol., 79(5), 431-454.

[142] Margesin, R., and Schinner, F. (2001). Biodegradation and bioremediation of hydrocarbons in extreme environments. Appl. Microbiol. Biotechnol., 56(5-6), 650-663.

[143] McClure, N.C., Fry, J.C., and Weightman, A.J. (1991). Survival and catabolic activity of natural and genetically engineered bacteria in a laboratory-scale activated-sludge unit. Appl. Environ. Microbiol., 57(2), 366-373.

[144] Mensah, K.A., and Forster, C.F. (2003). An examination of the effects of detergents on anaerobic digestion. Biores. Technol., 90(2), 133-138.

[145] Meriç, S., Kabdah, I., Tünay, O., and Orhon, D. (1999). Treatability of strong wastewaters from polyester manufacturing industry. Water Sci. Technol., 39(10-11), 1-7.

[146] Misra, C., and Gupta, S.K. (2001). Hybrid reactor for priority pollutanttrichloroethylene removal. Water Res., 35(1), 160-166.

[147] Miura, Y., Hiraiwa, M.N., Ito, T., Itonaga, T., Watanabe, Y., and Okabe, S. (2007). Bacterial community structures in MBRs treating municipal wastewater: Relationship between community stability and reactor performance. Water Res., 41(3), 627-637.

[148] Moe, W.M., and Qi, B. (2004). Performance of a fungal biofilter treating gasphase solvent mixtures during intermittent loading. Water Res., 38(9), 22592268.

[149] Moreno, J., and Buitrón, G. (1998). Respirometry based optimal control of an aerobic bioreactor for the industrial wastewater treatment. Water Sci. Technol., 38(3), 219-226. 
[150] Moreno, J.A., Betancur, M.J., Buitrón, G., and Moreno-Andrade, I. (2006). Event-driven time-optimal control for a class of discontinuous bioreactors. Biotechnol. Bioeng., 94(4), 803-814.

[151] Moreno-Andrade, I., Buitrón, G., Betancur, M.J., and Moreno, J.A. (2006). Optimal degradation of inhibitory wastewaters in a fed-batch bioreactor. J. Chem. Technol. Biotechnol., 81(4), 713-720.

[152] Morgan, J.W., Forster, C.F., and Evison, L. (1990). A comparative study of the nature of biopolymers extracted from anaerobic and activated sludges. Water Res., 24(6), 743-750.

[153] Morgan-Sagastume, F., and Allen, D.G. (2003). Effects of temperature transient conditions on aerobic biological treatment of wastewater. Water Res., 37(15), 3590-3601.

[154] Morgenroth, E., Sherden, T., Van Loosdrecht, M.C.M., Heijnen, J.J., and Wilderer, P.A. (1997). Aerobic granular sludge in a sequencing batch reactor. Water Res., 31(12), 3191-3194.

[155] Mörsen, A., and Rehm, H.J. (1987). Degradation of phenol by a mixed culture of Pseudomonas putida and Cryptococcus elinovii adsorbed on activated carbon. Appl. Microbiol. Biotechnol., 26(3), 283-288.

[156] Mösche, M., and Meyer, U. (2002). Toxicity of linear alkylbenzene sulfonate in anaerobic digestion: Influence of exposure time. Water Res., 36(13), 32533260.

[157] Munz, G., Gori, R., Mori, G., and Lubello, C. (2007). Powdered activated carbon and membrane bioreactors (MBRPAC) for tannery wastewater treatment: Long term effect on biological and filtration process performances. Desalination, 207(1-3), 349-360.

[158] Nachaiyasit, S., and Stuckey, D.C. (1997). The effect of shock loads on the performance of an anaerobic baffled reactor (ABR). 1. Step changes in feed concentration at constant retention time. Water Res., 31(11), 27372746.

[159] Nachaiyasit, S., and Stuckey, D.C. (1997). The effect of shock loads on the performance of an anaerobic baffled reactor (ABR). 2. Step and transient hydraulic shocks at constant feed strength. Water Res., 31(11), 2747-2754.

[160] Nagel, P., Urtubia, A., Aroca, G., Chamy, R., and Schiappacasse, M. (1999). Methanogenic toxicity and anaerobic biodegradation of chemical products in use in a brewery. Water Sci. Technol., 40(8), 169-176.

[161] Natarajan, R., Azerad, R., Badet, B., and Copin, E. (2005). Microbial cleavage of C-F bond. J. Fluorine Chem., 126(4), 425-436.

[162] Nicolella, C., van Loosdrecht, M.C.M., and Heijnen, S.J. (2000). Wastewater treatment with particulate biofilm reactors. J. Biotechnol., 80(1), 1-33.

[163] Nicolella, C., Zolezzi, M., Rabino, M., Furfaro, M., and Rovatti, M. (2005). Development of particle-based biofilms for degradation of xenobiotic organic compounds. Water Res., 39(12), 2495-2504.

[164] Ødegaard, H. (2006). Innovations in wastewater treatment: The moving bed biofilm process. Water Sci. Technol., 53(9), 17-33.

[165] Oliveira, T.A.C., and Livingston, A.G. (2003). Bioscrubbing of waste gassubstrate absorber to avoid instability induced by inhibition kinetics. Biotechnol. Bioeng., 84(5), 552-563. 
[166] Pai, S.-L., Hsu, Y.-L., Chong, N.-M., Sheu, C.-S., and Chen, C.-H. (1995). Continuous degradation of phenol by Rhodococcus sp. immobilized on granular activated carbon and in calcium alginate. Biores. Technol., 51(1), 37-42.

[167] Paraskeva, P., and Diamadopoulos, E. (2006). Technologies for olive mill wastewater (OMW) treatment: A review. J. Chem. Technol. Biotechnol., 81(9), 1475-1485.

[168] Patel, G.B., Agnew, B.J., and Dicaire, C.J. (1991). Inhibition of pure cultures of methanogens by benzene ring compounds. Appl. Environ. Microbiol., 57(10), 2969-2974.

[169] Patwardhan, A.W. (2003). Rotating biological contactors: A review. Ind. Eng. Chem. Res., 42(10), 2035-2051.

[170] Petersen, B., Gernaey, K., Henze, M., and Vanrolleghem, P.A. (2002). Evaluation of an ASM1 model calibration procedure on a municipal-industrial wastewater treatment plant. J. Hydroinformatics, 4(1), 15-38.

[171] Prado Acosta, M., Valdman, E., Leite, S.G.F., Battaglini, F., and Ruzal, S.M. (2005). Biosorption of copper by Paenibacillus polymyxa cells and their exopolysaccharide. World J. Microbiol. Biotechnol., 21(6-7), 1157-1163.

[172] Prats, D., Ruiz, F., Vazquez, B., and Rodriguez-Pastor, M. (1997). Removal of anionic and nonionic surfactants in a wastewater treatment plant with anaerobic digestion: A comparative study. Water Res., 31(8), 1925-1930.

[173] Prieto, M.B., Hidalgo, A., Rodríguez-Fernández, C., Serra, J.L., and Llama, M.J. (2002). Biodegradation of phenol in synthetic and industrial wastewater by Rhodococcus erythropolis UPV-1 immobilized in an air-stirred reactor with clarifier. Appl. Microbiol. Biotechnol., 58(6), 853-859.

[174] Pruden, A., Sedran, M., Suidan, M., and Venosa, A. (2003). Biodegradation of MTBE and BTEX in an aerobic fluidized bed reactor. Water Sci. Technol., 47(9), 123-128.

[175] Rajganesh, B., and Sublette, K.L. (1995). Biotreatment of refinery spent sulfidic caustics. Biotechnol. Prog., 11(2), 228-230.

[176] Rebac, S., Ruskova, J., Gerbens, S., Van Lier, J.B., Stams, A.J.M., and Lettinga, G. (1995). High-rate anaerobic treatment of wastewater under psychrophilic conditions. J. Ferm. Bioeng., 80(5), 15-22.

[177] Rintala, J.A., and Lepistö, S.S. (1998). Thermophilic anaerobic treatment of sulphur rich forest industry wastewater. Biodegradation, 9(3-4), 225-232.

[178] Sawada, T., and Nakamura, Y. (1987). Growth inhibitory and lethal effects of ethanol on Escherichia coli. Biotechnol. Bioeng., 29(6), 742-746.

[179] Schmidt, J.E., and Ahring, B.K. (1996). Granular sludge formation in upflow anaerobic sludge blanket (UASB) reactors. Biotechnol. Bioeng., 49(3), 229-246.

[180] Schmidt, J.E., and Ahring, B.K. (1997). Treatment of waste water from a multi product food-processing company, in upflow anaerobic sludge blanket (UASB) reactors: The effect of seasonal variation. Pure Appl. Chem., 69(11), 2447-2452.

[181] Schwartz-Mittelmann, A., and Galil, N.I. (2000). Biological mechanisms involved in bioflocculation disturbances caused by phenol. Water Sci. Technol., 42(1-2), 105-110.

[182] Schwarzenbeck, N., Erley, R., and Wilderer, P.A. (2004). Aerobic granular sludge in an SBR-system treating wastewater rich in particulate matter. Water Sci. Technol., 49(11-12), 41-46. 
[183] Seo, G.T., Ahan, H.I., Kim, J.T., Lee, Y.J., and Kim, I.S. (2004). Domestic wastewater reclamation by submerged membrane bioreactor with high concentration powdered activated carbon for stream restoration. Water Sci. Technol., 50(2), 173-178.

[184] Shao, C.Y., Howe, C.J., Porter, A.J.R., and Glover, L.A. (2002). Novel cyanobacterial biosensor for detection of herbicides. Appl. Environ. Microbiol., 68(10), 5026-5033.

[185] Smith, N.R., Yu, Z., and Mohn, W.W. (2003). Stability of the bacterial community in a pulp mill effluent treatment system during normal operation and a system shutdown. Water Res., 37(20), 4873-4884.

[186] Strachan, L.F., and Livingston, A.G. (1997). The effect of membrane module configuration on extraction efficiency in an extractive membrane bioreactor. $J$. Membr. Sci., 128(2), 231-242.

[187] Strotmann, U.J., Butz, B., and Bias, W.-R. (1993). The dehydrogenase assay with resazurin: Practical performance as a monitoring system and $\mathrm{pH}-$ dependent toxicity of phenolic compounds. Ecotox. Environ. Safety, 25(1), 79-89.

[188] Suidan, M.T., Flora, J.R.V., Boyer, T.K., Wuellner, A.M., and Narayanan, B. (1996). Anaerobic dechlorination using a fluidized-bed GAC reactor. Water Res., 30(1), 160-170.

[189] Suvilampi, J., Lehtomäki, A., and Rintala, J. (2003). Comparison of laboratoryscale thermophilic biofilm and activated sludge processes integrated with a mesophilic activated sludge process. Biores. Technol., 88(3), 207-214.

[190] Tatarazako, N., and Oda, S. (2007). The water flea Daphnia magna (Crustacea, Cladocera) as a test species for screening and evaluation of chemicals with endocrine disrupting effects on crustaceans. Ecotoxicology, 16(1), 197203.

[191] Tauriainen, S.M., Virta, M.P.J., and Karp, M.T. (2000). Detecting bioavailable toxic metals and metalloids from natural water samples using luminescent sensor bacteria. Water Res., 34(10), 2661-2666.

[192] Tay, S.T.-L., Moy, B.Y.-P., Jiang, H.-L., and Tay, J.-H. (2005). Rapid cultivation of stable aerobic phenol-degrading granules using acetate-fed granules as microbial seed. J. Biotechnol., 115(4), 387-395.

[193] Tay, S.T.-L., Moy, B.Y.-P., Maszenan, A.M., and Tay, J.-H. (2005). Comparing activated sludge and aerobic granules as microbial inocula for phenol biodegradation. Appl. Microbiol. Biotechnol., 67(5), 708-713.

[194] Tchobanoglous, G., Burton, F.L., and Stensel, H.D. (2002). Wastewater engineering: Treatment and reuse. $4^{\text {th }}$ ed. Metcalf and Eddy, Inc., McGraw-Hill, New York.

[195] Thiele, J.H., and Zeikus, J.G. (1988). The anion-exchange substrate shuttle process: A new approach to two-stage biomethanation of organic and toxic wastes. Biotechnol. Bioeng., 31(6), 521-535.

[196] Thuy, Q.T.T., and Visvanathan, C. (2006). Removal of inhibitory phenolic compounds by biological activated carbon coupled membrane bioreactor. Water Sci. Technol., 53(11), 89-97.

[197] Tomei, M.C., Annesini, M.C., Luberti, R., Cento, G., and Senia, A. (2003). Kinetics of 4-nitrophenol biodegradation in a sequencing batch reactor. Water Res., 37(16), 3803-3814. 
[198] Tomei, M.C., Annesini, M.C., and Bussoletti, S. (2004). 4-nitrophenol biodegradation in a sequencing batch reactor: Kinetic study and effect of filling time. Water Res., 38(2), 375-384.

[199] Tresse, O., Lorrain, M.-J., and Rho, D. (2002). Population dynamics of freefloating and attached bacteria in a styrene-degrading biotrickling filter analyzed by denaturing gradient gel electrophoresis. Appl. Microbiol. Biotechnol., 59(45), 585-590.

[200] Tripathi, C.S., and Allen, D.G. (1999). Comparison of mesophilic and thermophilic aerobic biological treatment in sequencing batch reactors treating bleached kraft pulp mill effluent. Water Res., 33(3), 836-846.

[201] Van der Roest, H.F., van Bentem, A.G.N., and Lawrence, D.P. (2002). MBRtechnology in municipal wastewater treatment: Challenging the traditional treatment technologies. Water Sci. Technol., 46(4-5), 273-280.

[202] Van Hulle, S.W.H., and Vanrolleghem, P.A. (2004). Modelling and optimisation of a chemical industry wastewater treatment plant subjected to varying production schedules. J. Chem. Technol. Biotechnol., 79(10), 1084-1091.

[203] Van Lier, J.B. (1996). Limitations of thermophilic anaerobic wastewater treatment and the consequences for process design. Antonie van Leeuwenhoek (Int. J. Gen. Molecular Microbiol.), 69(1), 1-14.

[204] Van Lier, J.B., Grolle, K.C.F., Stams, A.J.M., Conway de Macario, E., and Lettinga, G. (1992). Start-up of a thermophilic upflow anaerobic sludge bed (UASB) reactor with mesophilic granular sludge. Appl. Microbiol. Biotechnol., 37(1), 130-135.

[205] Van Lier, J.B., Groeneveld, N., and Lettinga, G. (1996). Development of thermophilic methanogenic sludge in compartmentalized upflow reactors. Biotechnol. Bioeng., 50(2), 115-124.

[206] Van Lier, J.B., Sanz Martin, J.L., and Lettinga, G. (1996). Effect of temperature on the anaerobic thermophilic conversion of volatile fatty acids by dispersed and granular sludge. Water Res., 30(1), 199-207.

[207] Van Lier, J.B., Lens, P.N.L., and Hulshoff Pol, L.W. (2001). Anaerobic treatment for $\mathrm{C}$ and $\mathrm{S}$ removal in "zero-discharge" paper mills: Effects of process design on S removal efficiencies. Water Sci. Technol., 44(4), 189-195.

[208] Van Lier, J.B., and Boncz, M.A. (2002). Controlling calcium precipitation in an integrated anaerobic-aerobic treatment system of a "zero-discharge" paper mill. Water Sci. Technol., 45(10), 341-347.

[209] Van Loosdrecht, M.C.M., and Heijnen, S.J. (1993). Biofilm bioreactors for wastewater treatment. Trends Biotechnol., 11(4), 117-121.

[210] Van Loosdrecht, M.C.M., and Henze, M. (1999). Maintenance, endogeneous respiration, lysis, decay and predation. Water Sci. Technol., 39(1), 107-117.

[211] Vargas, A., Soto, G., Moreno, J., and Buitrón, G. (2000). Observer-based timeoptimal control of an aerobic SBR for chemical and petrochemical wastewater treatment. Water Sci. Technol., 42(5-6), 163-170.

[212] Visvanathan, C., Thu, L.N., Jegatheesan, V., and Anotai, J. (2005). Biodegradation of pentachlorophenol in a membrane bioreactor. Desalination, 183(1-3), 455-464.

[213] Vogelaar, J.C.T., Klapwijk, A., Van Lier, J.B., and Rulkens, W.H. (2000). Temperature effects on the oxygen transfer rate between 20 and $55^{\circ} \mathrm{C}$. Water Res., 34(3), 1037-1041. 
[214] Vogelaar, J.C.T., Klapwijk, B., Van Lier, J.B., and Lettinga, G. (2002). Mesophilic and thermophilic activated sludge post treatment of anaerobic effluent: Sludge and wastewater characterisation using batch experiments. Biodegradation, 13(4), 261-271.

[215] Vogelaar, J.C.T., Van Lier, J.B., Klapwijk, B., De Vries, M.C., and Lettinga, G. (2002). Assessment of effluent turbidity in mesophilic and thermophilic activated sludge reactors-origin of effluent colloidal material. Appl. Microbiol. Biotechnol., 59(1), 105-111.

[216] Vogelaar, J.C.T., Bouwhuis, E., Klapwijk, A., Spanjers, H., and Van Lier, J.B. Mesophilic and thermophilic activated sludge post-treatment of paper mill process water. Water Res., 36(7), 1869-1879.

[217] Vogelsang, C., Husby, A., and Østgaard, K. (1997). Functional stability of temperature-compensated nitrification in domestic wastewater obtained with PVA-SBQ/alginate gel entrapment. Water Res., 31(7), 1659-1664.

[218] Vogelsang, C., Gollembiewski, K., and Østgaard, K. (1999). Effect of preservation techniques on the regeneration of gel entrapped nitrifying sludge. Water Res., 33(1), 164-168.

[219] Vogelsang, C., Wijffels, R.H., and Østgaard, K. (2000). Rheological properties and mechanical stability of new gel-entrapment systems applied in bioreactors. Biotechnol. Bioeng., 70(3), 247-253.

[220] Wang, Z., Liu, L., Yao, J., and Cai, W. (2006). Effects of extracellular polymeric substances on aerobic granulation in sequencing batch reactors. Chemosphere, 63(10), 1728-1735.

[221] Watanabe, K., Hino, S., and Takahashi, N. (1996). Responses of activated sludge to an increase in phenol loading. J. Ferm. Bioeng., 82(5), 522-524.

[222] Watanabe, K., Teramoto, M., and Harayama, S. (1999). An outbreak of nonflocculating catabolic populations caused the breakdown of a phenol-digesting activated-sludge process. Appl. Environ. Microbiol., 65(7), 2813-2819.

[223] Westmeier, F., and Rehm, H.J. (1985). Biodegradation of 4-chlorophenol by entrapped Alcaligenes sp. A 7-2. Appl. Microbiol. Biotechnol., 22(5), 301-305.

[224] Wilén, B.-M., Keiding, K., and Nielsen, P.H. (2000). Anaerobic deflocculation and aerobic reflocculation of activated sludge. Water Res., 34(16), 3933-3942.

[225] Wilén, B.-M., Nielsen, J.L., Keiding, K., and Nielsen, P.H. (2000). Influence of microbial activity on the stability of activated sludge flocs. Colloids Surf. B: Biointerfaces, 18(2), 145-156.

[226] Wiles, S., Whiteley, A.S., Philp, J.C., and Bailey, M.J. (2003). Development of bespoke bioluminescent reporters with the potential for in situ deployment within a phenolic-remediating wastewater treatment system. J. Microbiol. Methods, 55(3), 667-677.

[227] Wiles, S., Lilley, A.K., Philp, J.C., Bailey, M.J., and Whiteley, A.S. (2005). Calibration and deployment of custom-designed bioreporters for protecting biological remediation consortia from toxic shock. Environ. Microbiol., 7(2), 260-269.

[228] Winther-Nielsen, M., and La Cour Jansen, J. (1996). The role of the sludge in nitrification inhibition tests. Water Sci. Technol., 33(6), 93-100.

[229] Wise, A.A., and Kuske, C.R. (2000). Generation of novel bacterial regulatory proteins that detect priority pollutant phenols. Appl. Environ. Microbiol., 66(1), 163-169. 
[230] Wobus, A., and Röske, I. (2000). Reactors with membrane-grown biofilms: Their capacity to cope with fluctuating inflow conditions and with shock loads of xenobiotics. Water Res., 34(1), 279-287.

[231] Wolfaardt, G.M., Lawrence, J.R., Headley, J.V., Robarts, R.D., and Caldwell, D.E. (1994). Microbial exopolymers provide a mechanism for bioaccumulation of contaminants. Microb. Ecol., 27(3), 279-291.

[232] Wolfaardt, G.M., Lawrence, J.R., Robarts, R.D., and Caldwell, D.E. (1998). In situ characterization of biofilm exopolymers involved in the accumulation of chlorinated organics. Microb. Ecol., 35(3), 213-223.

[233] Woolard, C.R. (1997). The advantages of periodically operated biofilm reactors for the treatment of highly variable wastewater. Water Sci. Technol., 35(1), 199-206.

[234] Woolard, C.R., and Irving, R.L. (1994). Biological treatment of hypersaline wastewater by a biofilm of halophilic bacteria. Water Environ. Res., 66(3), 230-235.

[235] Woolard, C.R., and Irvine, R.L. (1995). Response of a periodically operated halophilic biofilm reactor to changes in salt concentration. Water Sci. Technol., 31(1), 41-50.

[236] Wu, W.-M., Bhatnagar, L., and Zeikus, J.G. (1993). Performance of anaerobic granules for degradation of pentachlorophenol. Appl. Environ. Microbiol., 59(2), 389-397.

[237] Xu, H., Tay, J.H., Foo, S.K., Yang, S.F., and Liu, Y. (2004). Removal of dissolved copper(II) and zinc(II) by aerobic granular sludge. Water Sci. Technol., 50(9), 155-160.

[238] Yan, G., and Allen, D.G. (1994). Biosorption of high molecular weight organochlorines in pulp mill effluent. Water Res., 28(9), 1933-1941.

[239] Yeom, S.H., and Yoo, Y.J. (1999). Removal of benzene in a hybrid bioreactor. Proc. Biochem., 34(3), 281-288.

[240] Yeom, S.-H., and Daugulis, A.J. (2001). Development of a novel bioreactor system for treatment of gaseous benzene. Biotechnol. Bioeng., 72(2), 156-165.

[241] Yi, S., Zhuang, W.-Q., Wu, B., Tay, S.T.-L., and Tay, J.-H. (2006). Biodegradation of $p$-nitrophenol by aerobic granules in a sequencing batch reactor. Environ. Sci. Technol., 40(7), 2396-2401.

[242] Zandvoort, M.H., Van Hullebusch, E.D., Peerbolte, A., Golubnic, S., Lettinga, G., and Lens, P.N.L. (2005). Influence of pH shocks on trace metal dynamics and performance of methanol fed granular sludge bioreactors. Biodegradation, 16(6), 549-567.

[243] Zhang, D., Wang, J., and Pan, X. (2006). Cadmium sorption by EPSs produced by anaerobic sludge under sulfate-reducing conditions. J. Hazard. Mat., 138(3), 589-593.

[244] Zhang, L.-L., Feng, X.-X., Xu, F., Xu, S., and Cai, W.-M. (2005). Biosorption of rare earth metal ion on aerobic granules. J. Environ. Sci. Health, 40(4), $857-867$.

[245] Zhuang, W.-Q., Tay, J.-H., Yi, S., and Tay, S.T.-L. (2005). Microbial adaptation to biodegradation of tert-butyl alcohol in a sequencing batch reactor. $J$. Biotechnol., 118(1), 45-53. 